\title{
Evaluation of bone fragility in endocrine disorders
}

\section{Cristina Eller-Vainicher ${ }^{1}$, Alberto Falchetti ${ }^{2}$, Luigi Gennari ${ }^{3}$, Elisa Cairoli2,4, Francesco Bertoldo ${ }^{5}$, Fabio Vescini ${ }^{6}$, Alfredo Scillitani ${ }^{7}$ and lacopo Chiodini ${ }^{2,8}$}

${ }^{1}$ Unit of Endocrinology Fondazione IRCCS Cà Granda - Ospedale Maggiore Policlinico Milan, Milan, Italy, ${ }^{2}$ Istituto Auxologico Italiano, IRCCS, Unit for Bone Metabolism Diseases and Diabetes \& Lab of Endocrine and Metabolic Research, Milan, Italy, ${ }^{3}$ Department of Medicine, Surgery and Neurosciences, University of Siena, Siena, Italy, ${ }^{4}$ Department of Pathophysiology and Transplantation, University of Milan, Milan, Italy, ${ }^{5}$ Bone Metabolism and Osteoncology Unit, Department of Medicine University of Verona, Verona, Italy, ${ }^{6}$ Endocrinology and Metabolism Unit, University-Hospital S. Maria della Misericordia Udine, Udine, Italy, 'Unit of Endocrinology and Diabetology, Ospedale 'Casa Sollievo della Soffererenza', IRCCS, San Giovanni Rotondo (FG), Italy, and ${ }^{8}$ Department of Clinical Sciences \& Community Health, University of Milan, Milan, Italy

Correspondence should be addressed to I Chiodini Email

iacopo.chiodini@unimi.it

\section{Abstract}

An underlying disease affecting bone health is present in up to 40 and $60 \%$ of osteoporotic postmenopausal women and men respectively. Among the disorders leading to a secondary form of osteoporosis, the endocrine diseases are highly represented. A frequent finding in patients affected with an endocrine-related forms of bone disease is that the skeletal fragility is partially independent of the bone density, since the fracture risk in these patients is related more to a reduction of bone quality than to a decrease of bone mass. As a consequence, bone mineral density evaluation by dual-X-ray absorptiometry may be inadequate for establishing the risk of fracture in the setting of the endocrinerelated forms of osteoporosis. In the recent years, several attempts to non-invasively estimating bone quality have been done. Nowadays, some new tools are available in the clinical practice for optimising the fracture risk estimation in patients with endocrine disorders. The aim of this review is to summarise the evidence regarding the role of the different imaging tools for evaluating bone density and bone quality in the most frequent forms of endocrine-related osteoporosis, such as obesity, diabetes, acromegaly, thyrotoxicosis, primary hyperparathyroidism, hypercortisolism and hypogonadism. For each of these disorders, data regarding both the current available tools and the future possible new techniques for assessing bone fragility in patients with endocrine diseases are reported.

\section{Invited author's profile}

Iacopo Chiodini is an Associate Professor in Endocrinology at the University of Milan (Italy) and Head of the Unit for Bone Metabolism Diseases and Diabetes of IRCCS Istituto Auxologico Italiano in Milan (Italy). Since 1994 his scientific research has been centred on the involvement of bone in endocrine diseases, particularly acromegaly and overt and subclinical hypercortisolism. Currently, he is focussing his scientific interest on the diagnosis and therapy of subclinical hypercortisolism, bone involvement in parathyroid diseases and in metabolic syndrome. He is the co-author of 347

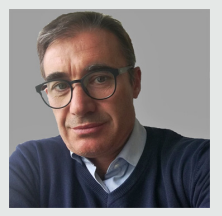
publications (125 papers on peer reviewed Journals, h-index by Scopus 35). He has been invited speaker or chair at more than 130 national and international meetings on the topics of bone involvement in endocrine diseases and diabetes, pathophysiology and therapy of osteoporosis and subclinical hypercortisolism. 


\section{Introduction}

Osteoporosis is a skeletal disorder characterised by compromised bone strength predisposing a person to an increased risk of fracture (1). Bone strength primarily reflects the material composition and structural design of bone by the integration of bone mineral density (BMD) and bone quality (1). The latter concept mainly include bone geometry (bone size, shape), bono macro- and microarchitecture (e.g. connectivity and thickness of trabeculae, thickness and porosity of cortical bone), the balance and rate of bone remodelling, bone mineralisation and the type and organisation of collagen or other components of the bone matrix.

Osteoporosis is classified as 'primary' when it occurs in the absence of an underlying disease and as 'secondary' when it is due to an underlying disease (2). It is known that up to $40 \%$ of postmenopausal women and $60 \%$ of men have factors contributing to osteoporosis when evaluated for underlying causes of the disease (2). Among the disorders leading to a secondary form of osteoporosis, the endocrine diseases are largely represented (2) and listed in Table 1. Patients affected with endocrine-related forms of osteoporosis frequently experience fragility fractures in the presence of a normal or slightly reduced $\mathrm{BMD}$, since the fracture risk in these forms is related more to a reduction of bone quality than to a decrease of BMD (2). As a consequence, the BMD evaluation by, for example, dual-X-ray absorptiometry (DXA), which is of great importance in evaluating the fracture risk in primary osteoporosis (i.e. a T-score value $\leq-2.5$ ), may be inadequate for establishing the risk of fracture in the setting of the endocrine-related forms of osteoporosis.

In the recent years, several attempts to non-invasively estimating bone quality have been done. Nowadays, some new tools are available in the clinical practice for optimising the fracture risk estimation in patients with endocrine disorders affecting bone. The aim of this review is to summarise the evidences regarding the

Table 1 Main endocrine disorders associated with an increased risk of fractures.

\section{Endocrine disorders}

Cushing syndrome

Acromegaly

Thyrotoxicosis

Primary hyperparathyroidism

Primary hyperaldosteronism

Diabetes

Male hypogonadism

Obesity role of the different imaging tools for evaluating bone density and bone quality in the most frequent forms of endocrine-related osteoporosis. Although in studies examining secondary causes of osteoporosis, low vitamin $\mathrm{D}$ levels are consistently highlighted as the most common biochemical abnormality, we will not address this issue, since hypovitaminosis $\mathrm{D}$ is an important contributor to bone fragility, but it is not specific of a particular endocrine disorder influencing bone health. Finally, even though the mineralisation disorders may have an endocrine basis, we believed that addressing this issue was beyond the scope of the present review.

\section{Obesity}

Morbid adipose tissue accumulation may be regarded as a quite common disorder in a variety of endocrine diseases, although the factors accounting for the development of obesity in endocrinopathies have not been clearly identified. It is also well known that adipose tissue is regarded by now as an important endocrine organ since it produces several biologically active substances, for example, adipokines, with paracrine and endocrine action potentially leading to severe disorders of the endocrine system. Consequently, it is not far from the truth to consider obesity as an endocrine disorder more than a dysmetabolic condition. However, obesity has a complex and still poorly understood relationship to bone health. A fracture-related morbidity seems to be higher in obese than in non-obese women (3). It is also known that higher fat depots may have negative effects on bone, since both cytokines produced by visceral fat may exert a proresorptive effect and high intramuscular fat accumulation is associated with poorer muscle function, attenuating loading effects and increasing falls risk, partly similar to what was observed also in T2DM (4). In a study published in 2000, the waist-hip ratio (WHR) index was associated with the risk of hip fracture (5), and later visceral adipose tissue (VAT) also was positively associated with nonspine fractures (6). A recent systematic review and meta-analysis of prospective studies reported that abdominal obesity was positively associated with the risk of hip fracture (7).

A direct positive correlation between BMI and BMD has been reported in the literature $(8,9)$. Thus, in the past years, obesity status was believed to be protective against fragility fractures. Lately, several studies argued that obesity, as defined by WHO criteria by the a BMI equal to or above $30 \mathrm{~kg} / \mathrm{m}^{2}$, could no longer be regarded as a real protector from bone fragility. In fact, several 
Table 2 PROs and CONs in obesity and bone mass (BMD) interrelationship.

PROs
Mechanical load
Increased androgen levels (women)
Conversion from androgen into oestrogen
Increased levels of free sex hormones
Secretion of insulin and amylin by beta cells
Increased glucagon-like peptide 2
Adipokines
CONs
Reduced insulin-related signalling (insulin resistance)
Adipokines
Hyperglycaemia in obese-T2DM subjects
Inflammation and pro-inflammatory cytokines
Dyslipidaemia
Reduced vitamin D levels/secondary hyperparathyroidism/
calcium malabsorption
Hypogonadism
Abnormal muscular metabolism/function

findings demonstrated that while on the one hand BMI is associated with increased risk of fracture at some skeletal sites, on the other hand, it may be protective at others skeletal sites, representing the so-called obesity paradox (8). Table 2 reports a summary concerning some of the factors, pros and cons, potentially associated in the interrelationship between obesity and bone mass.

DXA essentially focuses on the mineralised component, and it is still the most widely used tool to assess BMD to estimate the bone fragility fracture risk. In a study on obese patients, more than $50 \%$ of subjects, with at least one vertebral fracture, exhibited a normal or only slightly reduced $\mathrm{BMD}$, but not osteoporosis, and vertebral fractures occurred 4.4-fold more frequently in patients than controls, thus suggesting that in obese population DXA may not represent an accurate instrument to adequately estimate the fracture risk (10). Data on the risk of hip fractures in obese patients are not conclusive even for the influence of diabetes (11). In fact, since obesity and excess fat mass, especially VAT, are increasing risk factors for low BMD and fragility fractures (3), in obese or overweight subjects the BMD measured by DXA may not be a reliable method of assessing fracture risk. Finally, by a practical point of view, in very obese patients, especially in whom the body weight exceeds the limit for the DXA table, the BMD assessment should be performed not only at the 'classical' lumbar and femoral sites, but also at the non-dominant forearm. In obese patients undergoing bariatric surgery or medical (diet) weight loss regimens with anticipated large weight loss, the DXA total body composition with regional analysis can be used in order to assess fat and lean mass changes when weight loss exceeds approximately 10\%, but not for fracture risk assessment (12).

Recently, a dedicated algorithm for the assessment of bone microarchitecture at the lumbar spine (LS), the trabecular bone score (TBS), has been introduced. TBS is a textural index based on evaluating pixel grey-level variations in the LS DXA image, providing an indirect index of bone architecture. Thus, TBS can assess bone quality and provide information about fracture risk independent of BMD. Interestingly, BMD has been reported to correlate positively with BMI, whereas TBS has been described to be inversely related to BMI, suggesting that an increase in BMI has a negative impact on bone quality (13). Therefore, TBS seems to be a better measure of bone fragility in individuals who are obese/overweight and useful in assessing osteoporotic fracture risk, with lower TBS values associated with increased fracture risk. Lately, a prospective study on 38 morbidly obese white women, undergoing Roux-en-Y gastric bypass (RYGB) procedure, followed up to 3 years, demonstrated that the fracture risk, calculated by FRAX ${ }^{\circledR}$ algorithm (University of Sheffield, Sheffield, UK), with and without adjustment by TBS, was low, and the authors interestingly concluded that women undergoing RYGB in the mid-term have a preserved bone microarchitecture assessed by TBS (14). However, larger randomised prospective clinical trials will be necessary before suggesting TBS as a significant valuable technique for the prediction of fracture risk in obese subjects. A new tool to assess bone health, the $\mathrm{BMD} / \mathrm{BMI}$ ratio has been recently presented, at the 27 th American Association of Clinical Endocrinologists (AACE) meeting, held, on May 2018, in Boston, MA, US (https:// www.medscape.com/viewarticle/896882), by Watanabe and co-authors. They suggested such a simple measure as an important new tool to potentially and easily assess the risk fracture in obese patients, particularly when the bone strength could be linked to the presence of impaired metabolic health. They investigated a large Caucasian cohort of more than 2000 overweight or obese patients ( $82 \%$ female, aged $45 \pm 12$ years, mean BMI $36.5 \pm 6.2 \mathrm{~kg}$ / $\mathrm{m}^{2}$ ) by assessing the body composition, and both DXA LS BMD and TBS. Confirmation of the association between increased BMI, increased BMD and decreased TBS values has been obtained. The LS BMD/BMI ratio was more strongly correlated with TBS than LS BMD. In obese subjects with metabolic syndrome, the LS BMD was similar to that of metabolically healthy subjects, but both TBS and BMD/BMI ratio were significantly lower. All these preliminary findings suggest that the BMD/ 
BMI ratio offers a simple tool for assessing the risk of fracture in obese subjects (https://www.medscape.com/ viewarticle/896882). However, it will be necessary to wait for the effective publication of these data, and their possible replication in other studies.

As above suggested, obese patients may have normal DXA measured BMD values, despite of a possible deterioration in bone architecture and, consequently, an increased prevalence of vertebral fractures (13). The spinal deformity index (SDI) conjugates and integrates both the number and severity of vertebral fractures as a single parameter and it has been suggested to be an indirect surrogate marker of bone microarchitecture (15). According to this technique, fractures assessed on lateral thoracolumbarspine radiographs were defined as reductions of more than $20 \%$ in anterior, middle or posterior vertebral height. From lateral spine radiographs, each vertebra is visually assessed as intact (semiquantitative, SQ, grade 0 ) or as having approximately mild (20-25\% compression), moderate (25-40\% compression) or severe ( $>40 \%$ compression) deformity (SQ grades 1,2 and 3, respectively). Subsequently for each subject the SDI was calculated by summing the SQ grade for each of the 13 vertebrae from T4 to L4. In a prospective study on 54 obese subjects ( $51 \pm 16$ years, 10 males, 44 females), SDI was found to be an useful index of vertebral fractures risk, as it has been demonstrated in postmenopausal osteoporotic females (10).

Beyond the 'classical' thoraco-lumbar projection radiography, DXA scanners can also be utilised for vertebral fracture assessment (VFA) of a lateral image of T4 to L4 spine, with a significantly reduced dose than 'classical' X-rays and a high degree of accuracy in diagnosing fracture (16). This is of importance since the presence of a prevalent asymptomatic vertebral fractures is a strong predictor of future fractures (17). However, sometimes in large obese subjects, neither DXA nor the VFA can be performed because their weight exceeds the limit for DXA table, or the important thickness of VAT may alter the reliability of the result (12). Further imaging may be required where other underlying pathology is suspected and magnetic resonance imaging (MRI), computed tomography (CT) and nuclear medicine or positron emission tomography CT may be used.

Osteoporosis associates with an increased bone marrow fat (BMF) due to a shift in the differentiation pattern of mesenchymal stem cells that preferentially move more towards the adipocytes phenotype rather than to osteoblastic lineage (18). More recently, several studies have strongly evidenced the role that also non-mineralised bone component potentially play in determining bone health $(18,19)$. In particular, such studies stand that bone marrow, primarily consisting of adipocytes (yellow marrow areas) or adipocytes and haematopoietic red blood cells (red marrow areas), fills the cavities present at the trabecular bone level, and higher BMF fraction (BMFF) have been associated with lower BMD values $(20,21,22,23,24,25,26)$. Moreover, in comparison to white and brown adipose tissue depots or ectopic fat depots in the human body, BMF exerts a distinctly different function, potentially playing an important role in the pathophysiology of metabolic disorders and fragility fracture risk (26). For these reasons, MRI and magnetic resonance spectroscopy (MRS) have been suggested as ideal imaging techniques for a noninvasive investigation of BMF properties. However, MRIbased evaluation of BMF may provide an interesting insight into the pathophysiology of osteoporosis and/or obesity, and it could be useful in the investigations on the association of bone and metabolic disturbances.

BMFF may represent a negative predictor of bone microarchitecture and mechanical properties in obese men, and it has been positively associated with ectopic and serum lipid levels in obese men and women and to their increase following a 6-month growth hormone administration in obese women (27). In a study on 47 premenopausal women, the vertebral BMFF was positively associated with VAT and inversely associated with insulinlike growth factor 1 (IGF-1), suggesting that VAT might have negative effects on bone health, partially mediated by IGF-1, a regulator of both fat and bone lineage (28). Changes of the BMF and bone mass after RYGB surgery have been investigated on 11 women, six diabetic and five non-diabetic, undergone RYGB, LS MRS, anthropometric measurements, whole body fat and BMD measurements. A positive correlation between age and BMF content was described, and, interestingly, mean BMF decreased in the diabetic subjects, versus non-diabetic women who showed only a small change, suggesting that BMF may behave differently than other fat depots in patients without diabetes after RYGB (24). However, further studies with larger number of specimens are needed in order to investigate whether the BMF has an effect on bone strength after correcting for the contribution of BMD. The currently available MRI-based methods, including MRS and water-fat imaging, enable the non-invasive extraction of the BMFF and unsaturation, but the knowledge of the underlying mechanisms is extremely scarce and, above all, no information is available in relation to their effective role in the clinical evaluation of fracture risk in subjects 
with reduced bone mass; therefore, at the moment, their use is reserved only for research purposes.

Finally, an interesting review on bone health after bariatric surgery in obese patients evaluated also the bone mass technical approaches in this obese population and addressed the use of quantitative computed tomography (QCT)-based modalities to examine volumetric BMD and compartment-specific density and microstructure (29). Promising results come out, indicating that QCT technology can strengthen and advance the knowledge base. In particular, a pronounced reduction of bone mass at appendicular skeleton has been demonstrated by high-resolution (HR) peripheral quantitative computed tomography (pQCT, HR-pQCT), evaluating volume BMD (vBMD), other than in bone mass at the axial skeleton as assessed by DXA and QCT $(30,31,32,33)$, even if it has been reported that HR-pQCT underestimates vBMD decrease when performed on important reduction in fat. (32). HR-pQCT studies seem also to adequately provide an individual analysis at both cortical and trabecular compartments, allowing for the identification of distinct pattern of bone loss. In fact, some studies revealed that the decrease in total $\mathrm{vBMD}$, at the radius level, mainly reside in decreasing of trabecular $\mathrm{vBMD}$, whereas the tibial total vBMD mainly reduces either within the cortical compartment or within both trabecular and cortical compartments $(31,32,33)$. By this approach, information on bone microstructure and estimated strength at the appendicular skeleton can also be extrapolated (30, 31, 32, $33,34,35)$. In obese bariatric subjects, undergoing different surgical approach, the HR-pQCT analysis provided a quantitative characterisation of bone microstructure at compartmental level, documenting deterioration in either trabecular or cortical architecture (30, 31, 32): (i) a decrease of trabecular number and trabecular separation within the trabecular bone, with consequent increased heterogeneity $(31,32,33)$; (ii) a decrease of the cortical thickness and an increase of the trabecular area, due to endocortical resorption $(26,27,28)$; (iii) a pronounced increase of cortical porosity $(31,32,33)$. All these findings suggest also reduction of the bone strength at both the radius and the tibia $(31,32)$ with the consequent increase in fracture risk.

\section{Diabetes}

Emerging evidence suggests that diabetes exacerbates agerelated reductions in bone strength and quality leading to increased bone fragility (36). In fact, type 1 diabetes
(T1D) is associated with four- to six-fold increased risk of fractures that begins in childhood and extends across the life span. Likewise, a similar, albeit less marked, increase in the prevalence of fragility fractures has also been described in type 2 diabetes (T2D), particularly affecting the hip and other peripheral skeletal sites (37). While in T1D patients a modest decrease in BMD at trabecular and cortical sites is generally described, in T2D patients normal or even higher than normal BMD levels are frequently observed (37). Collectively, these findings indicate that BMD measurement does not consistently account for the increase in bone fragility in diabetes and suggest that abnormalities in bone microarchitecture and/or material composition (not captured by DXA) are likely responsible for the observed increase in fracture risk in either T1D and T2D diabetic patients.

The mechanisms underlying bone fragility in diabetes have not been clearly established and might differ, at least in part, between T1D and T2D, due to differences in the onset of disease, in insulin concentrations and resistance, as well as in the therapeutic approaches $(36,38)$. Common mechanisms might include co-morbidities and increased risk of falls associated with diabetes or direct effects of hyperglycemia on the skeleton such as a suppression of bone turnover and excessive accumulation of advanced glycation end products on collagen fibrils, which have an impact on bone quality and strength (36).

Based on the above considerations, the stratification of fracture risk in diabetes, particularly in T2D patients, cannot exclusively rely on the DXA measurement of BMD (either alone or in combination with the conventional risk factors for fracture) as it occurs in postmenopausal osteoporosis (39). Likewise, the algorithms such as FRAX, the WHO Fracture Risk Assessment Tool, underestimate fracture risk in T2D patients $(31,40)$. Obviously, the finding of a low BMD still remains predictive of bone fragility in diabetic patients, as in the general population, and thus, has to be considered useful for estimating the fracture risk (39). In fact, for each 1 SD decrease in $\mathrm{BMD}$, the risk of hip fracture is almost equally doubled in individuals with or without T2D (35). However diabetic patients generally have fractures at higher BMD levels than the general population, with T-score levels often above the osteoporotic range. Thus, concerning T2D, it has been estimated that a similar increase in hip fracture risk than in non-diabetic subjects occurs at $0.6 \mathrm{SD}$ and 0.4 SD higher BMD levels in women and men, respectively (40). In addition to BMD measurement, a spinal X-ray should be mandatory in diabetic patients with a previous fragility fracture or in those with diabetic complications, 
particularly in the presence of a poorly controlled disease. Indeed, when investigated by a lateral spine radiograph, up to a third of postmenopausal T2D women showed asymptomatic, morphometric, vertebral fractures (42), that per se represent a major risk factor for subsequent fractures (43).

As a consequence of the difficulties of relying on BMD to assess fracture risk in diabetes, other imaging techniques have been investigated in the past few years to better understand the mechanisms of skeletal fragility in either T1D or T2D (44), as summarised in Table 3. Different cross-sectional and retrospective reports have suggested that TBS is often reduced in either T1D or T2D (44) and that might predict fracture risk better than BMD $(44,45,46)$.

The hip structural analysis (HSA) represents an additional tool that can be applied to DXA in order to obtain information on bone geometry and indirectly assess the bone resistance to axial compressive forces (47). However, although a weaker geometry (e.g. a narrower neck width) and compromised estimates of skeletal load response (e.g. a lower buckling ratio) have been described using HSA in some cohorts of T2D patients (47), their additive role on the prediction of fractures remains to be established. Notwithstanding the low cost and the wide availability of quantitative ultrasound (QUS) devices of the calcaneous and the phalanxes, limited information has been released about their use in diabetic patients. Available information from cross-sectional studies indicate that QUS parameters may be reduced in patients with either T1D or T2D (48), but conflicting data exist concerning their predictive role in discriminating patients with fragility fractures $(48,49)$.
Moreover, a correlation between reduced QUS parameters and poor glyco-metabolic control or peripheral nerve dysfunction was also described (50).

Recently, QCT and HR-pQCT of the distal radius and tibia have been employed to obtain a 3D assessment of bone size, vBMD, bone macro- and microarchitecture (e.g., cortical porosity and trabecular connectivity). The use of these techniques indicated that T1D patients are at risk for smaller sizes of the appendicular bones at the end of pubertal growth and generally shows thinner cortices as well as thinner and more widely spaced trabeculae $(44,51)$. These structural bone deficit appears more pronounced in the presence of microvascular complications (52). Similar studies in T2D patients have demonstrated preserved indices of trabecular microarchitecture but increased cortical porosity, particularly in T2D females with fragility fractures $(53,54,55,56)$.

Very limited information is available concerning the use of MRI to assess trabecular and cortical bone parameters at both axial and peripheral skeleton and their role in the stratification of fracture risk in diabetic patients (25). Notably MRS of the vertebral bodies evidenced an altered BMF composition (with lower unsaturation of bone marrow lipids) in postmenopausal women with fragility fractures and T2D (21). This approach might represent a promising tool for fracture risk assessment in diabetes, given the negative role of BMF on the commitment of mesenchymal stem cells towards the osteoblast lineage and its detrimental implications one BMD and structural bone integrity $(18,25,26)$.

However, despite the promising results from retrospective and cross-sectional observations and the

Table 3 Fragility fracture risk and most frequent findings in the evaluation of bone mineral density and bone quality in the endocrine-related forms of osteoporosis.

\begin{tabular}{l}
\hline Disorder \\
\hline Obesity \\
Type 2 diabetes \\
Type 1 diabetes \\
Acromegaly \\
Overt hyperthyroidism \\
Subclinical Hyperthyroidism \\
Primary Hyperparathyroidism \\
Overt Hypercortisolism \\
Subclinical hypercortisolism \\
Hypogonadism in CTIBL
\end{tabular}

$\frac{\overline{\text { VFx risk }}}{}$
$\uparrow$
$\uparrow$
$\uparrow \uparrow$
$\uparrow \uparrow$
$\uparrow$
$\uparrow *$
$\uparrow$
$\uparrow \uparrow \uparrow$
$\uparrow \uparrow$
$\uparrow \uparrow$
$\uparrow \uparrow$

\begin{tabular}{l} 
Hip Fx risk \\
\hline N.A. \\
$\uparrow$ \\
$\uparrow \uparrow \uparrow$ \\
N.A. \\
$\uparrow$ \\
$\uparrow$ \\
$\uparrow$ \\
$\uparrow$ \\
N.A. \\
$\uparrow \uparrow$ \\
\hline
\end{tabular}

\begin{tabular}{l}
\hline DXA \\
\hline N/High \\
N/High \\
$\downarrow \downarrow$ \\
$N$ \\
$\downarrow \downarrow$ \\
$\downarrow \downarrow$ \\
$\downarrow$ \\
$\downarrow \downarrow$ \\
$\downarrow / N$ \\
$\downarrow / N$
\end{tabular}

TBS

Reduced

Available data from other imaging tools

Reduced QUS, HSA, QUS, QCT, HR-pQCT, MRI, MRS for BMF estimates Reduced QUS, QCT, HR-pQCT

Reduced HR-pQCT

NA NA

Reduced QCT, HR-pQCT, HAS

Reduced QUS

Reduced QUS, QCT

Reduced QUS, QCT

Reduced MRI, QCT, MDCT

*In postmenopausal women.

$\uparrow$ up to two-fold increased; $\uparrow \uparrow 2-5$ fold increased; $\uparrow \uparrow \uparrow$ more than five-fold increased; $\downarrow \downarrow$ severely reduced (i.e. T-score $\leq-2.5$ ); $\downarrow$ reduced (i.e. T-score between -1.0 and -2.5); N, normal (T-score >-1.0); BMF, bone marrow fat; CTIBL, cancer treatment-induced bone loss; HAS, hip structural analysis; HR-pQCT, high-resolution peripheral QCT; MDCT: multidetector-row computed tomography; MRI, magnetic resonance imaging; MRS, magnetic resonance spectroscopy; N.A., data not available; QCT, quantitative computed tomography; QUS, quantitative ultrasound. 
positive indications from experimental studies, the clinical relevance of imaging techniques other than DXA and vertebral morphometry for the prediction of fracture risk in patients with diabetes needs to be confirmed on a prospective basis and their scarce availability and high cost do not consent their routine use.

\section{Acromegaly}

Bone cells represent a target for the growth hormone (GH) and for its mediator, the insulin-like growth factor 1 (IGF1). These hormones mainly act on osteoblasts by inducing their differentiation and by enhancing their function. To a lesser extent IGF-1 may also activate osteoclasts through an increase of RANKL production. Pituitary adenomas overproducing GH cause acromegaly, a disease that induces bone enlargement, particularly in extremities (57). Until recent years, acromegalic patients have been considered as having high bone mass, but in the last decade a large body of evidence have emerged as to the presence of fragility fractures in people with acromegaly (57).

The attempt to measure BMD by means of a traditional method like DXA has given inadequate results in acromegaly. Importantly, spine BMD is usually normal in this disease, while hip BMD may even be higher than normal (57).

Notwithstanding the high bone mass acromegalic patients show an up to eight-fold increased rate of vertebral fragility fractures that may be explained by a reduction of bone quality rather than bone quantity. An increased cortical thickness and porosity and a reduced trabecular thickness with increased trabecular separation have been demonstrated in acromegalic patients (58); therefore, it is reasonable that other methods possibly measuring bone quality have been studied. Recently, two recent papers focused on the role of TBS in acromegaly. Hong and co-authors found lower values of TBS in acromegalic men and women than in matched controls, while no difference in BMD has been observed between the two groups (59). The second study demonstrated that acromegaly treatment increases BMD but contemporarily reduces TBS by $3 \%$ in both genders, with males tending to a more pronounced, but not significantly different, TBS decrease than females (60).

Another method that is used to measure bone quality is HR-pQCT, which by analysing the distal radius and tibia allows the in vivo assessment of both bone microarchitecture and volumetric BMD. Using HR-pQCT in 82 patients with acromegaly, Madeira et al. have found a severe deterioration of trabecular bone microarchitecture that was correlated with patients' gonadal status rather than with the presence of type 2 diabetes or the activity of the disease. Therefore, a sub-analysis was performed on 45 eugonadal acromegalic patients compared with 45 healthy controls. The patients showed lower trabecular volumetric bone density, bone volume to tissue volume and trabecular number than controls. Moreover they had higher trabecular separation and spacing than healthy subjects (61). All these findings can be associated with greater bone fragility, that, as previously demonstrated, is increased by hypogonadism (62).

Although eugonadal acromegalic patients show better bone quality than hypogonadal ones, a deterioration in trabecular microstructure of the radius has been demonstrated also in males with normal testosterone suggesting that acromegaly may overwhelm the protective role of sex steroids (63).

Also cortical bone is altered in acromegaly as both increased cortical porosity and reduced cortical strength have been demonstrated by several papers $(58,60,63)$. A recent paper evaluated trabecular and cortical parameters at distal radius level, by means of a HR-pQCT system, in 40 acromegalic patients and 21 healthy subjects (65). Patients with acromegaly showed lower bone volume/ trabecular volume $(\mathrm{BV} / \mathrm{TV})$ ratio and mean trabecular thickness as well as a greater trabecular separation than controls, but no difference between the two groups was observed with regard to cortical thickness and porosity. As compared to acromegalic patients without vertebral fractures, acromegalic patients with vertebral fractures showed lower BV/TV ratio and both greater trabecular separation and higher cortical porosity, but they did not differ in terms of cortical thickness and porosity (65). These results are very interesting as they show an increase of both cortical area and thickness together with a higher cortical porosity, reflecting a normal response to the enhanced bone turnover induced by GH and IGF-1 excess. Generally the increase of cortical pores reduces the resistance to mechanic loads, but in this very case, the simultaneous cortical bone enlargement seems to counteract the reduction of bone stiffness. The authors hypothesise that the difference in trabecular and cortical bone response to enhanced turnover may account for the described difference in fracture occurrence in acromegaly (i.e. increased risk for vertebral, but not appendicular fractures) (66). In contrast with these results a recent paper by Malgo et al. has investigated cortical strength by means of microndentation, a novel technique that allows the in vivo measuring of the so-called 'Bone 
Material Strength Index (BMSi)' (64). Patients with wellcontrolled acromegaly showed significantly lower BMSi values than healthy controls These results seem to suggest a reduced cortical bone strength in acromegaly that may be a reflection of persistent alterations in the material properties of cortical bone even after cessation of the disease (64).

In conclusion, a growing body of evidence in the last 10-15 years have shown an increased rate of fractures in acromegaly, particularly at the vertebral level, that are strictly correlated with a deterioration of bone microstructure caused by GH and IGF-1 overproduction. DXA is the most efficient way to measure bone mineral density in the general population and it show a very good correlation with fracture risk; nevertheless its efficacy in acromegaly is poor as BMD is generally normal in this disease, particularly at the hip level. Therefore as we have learned with other diseases, like glucocorticoid-induced or T2D osteoporosis, DXA does not represent a valid tool for fracture risk estimation in acromegaly. Promising results are coming from the few studies on TBS, on HR-pQCT or on microindentation as all these methods seem to be able to estimate bone quality. In particular, pQCT may represent a new method for discriminating acromegalic patients with vertebral fractures and it is a good prospect for predicting fracture occurrence in acromegaly. Further studies are necessary in order both to confirm these data and to test new methods for the assessment of bone quality in acromegaly.

\section{Thyrotoxicosis}

Thyroid hormones have important effects on skeletal development, linear growth and the maintenance of adult bone mass and strength. Thyroid gland mainly secrets thyroxine (T4) that is consequently metabolised in the active hormone 3,4,3'-L-triiodothyronine that enters the cellular nucleus where activates thyroid hormone receptor $\alpha$ or $\beta(\operatorname{TR} \alpha, \operatorname{TR} \beta)$. TR $\beta$ is the main receptor expressed in the hypothalamus and pituitary where it mediates negative feedback control, regulating thyroid-stimulating hormone (TSH) secretion, while TR $\alpha$ is the main receptor expressed in the skeleton. During childhood thyroid hormones accelerates skeletal development and bone maturation. Indeed, almost all pre-pubertal children with thyroid hormone excess have tall stature at diagnosis, with a height SD score significantly greater than that of their parents. However, this accelerated bone maturation, with a premature fusion of the growth plate, may lead to an adult short stature. In the adults, thyroid hormone stimulate bone turnover via increased osteoclastic bone reabsorption (67). The thyroid hormones excess causes a reversible bone loss due to an expansion of the re-modelling space and an irreversible loss due to a negative net bone balance and eventually an increased risk of trabecular perforations $(68,69)$.

Overt hyperthyroidism is a well-established cause of high bone turnover osteoporosis, resulting in an increased susceptibility to fracture. However, even subclinical hyperthyroidism, both endogenous and exogenous (i.e. TSH-suppressive therapy), which is characterised by normal thyroid hormones level and suppressed TSH, seems to be associated with an increased risk of fracture. TSH receptor is expressed also in chondrocytes, osteoblasts and osteoclasts and TSH is thought to exert a positive direct effect in bone metabolism (68).

The effects of overt hyperthyroidism on bone mineralisation have widely been documented by DXA. A decrease in BMD is present at all skeletal sites, including spine, femur, radius and total body, and it is greater in postmenopausal women. The close relationship between observed and BMD-estimated fracture risk could indicate that most of the changes in fracture risk are related to changes in BMD, and that other factors, such as an increased risk of falls, play a minor role (69). However, importantly, in the meta-analysis of a Vestergaard and co-authors, the increased risk of hip fracture was independent of hip BMD (69). Thus, in the condition of thyroid hormone excess, components of bone fragility that are entirely independent of conventional BMD may be present.

After a diagnosis of hyperthyroidism is made and after at least 1 year of treatment with anti-thyroid drugs BMD increases and returns in the normal range for age and sex within 5 years; in parallel, the fracture risk, which is twoto three-fold increased at both femur and spine in patients with overt hyperthyroidism, returns to normal after 1 year of treatment, even without specific anti-osteoporotic therapy (69). Interestingly, BMD increases above the expected from 1 to 4 years after diagnosis of hyperthyroidism. This may be explained by the idea that the normalisation of thyroid hormone levels induces a decrease in remodelling activity to subnormal levels and, consequently, a reduction in the remodelling space in this period. Following a lag time of 5 years or more, normal bone turnover will resume again, expanding the remodelling space to normal size and resulting in normal BMD levels (69).

As observed in overt hyperthyroidism, postmenopausal women with subclinical hyperthyroidism show 
reduced BMD evaluated by DXA, while data in men and premenopausal women are more controversial. A recent paper shows that the annualised rate of bone loss at hip is increased two- or three-fold in individuals with subclinical hyperthyroidism, especially in those with TSH below $0.10 \mathrm{mIU} / \mathrm{L}$ and high-normal free thyroxine levels (70). In keeping, recent data show that subclinical hyperthyroidism is associated with an increased risk for hip and other fractures, with the highest risks in individuals with suppressed TSH (below $0.10 \mathrm{mIU} / \mathrm{L}$ ), in those with endogenous subclinical hyperthyroidism and in patients above 60 years of age (71).

Nevertheless, in subclinical hyperthyroidism, DXA may not represent the best tool to detect bone damages and fracture risk, as in subclinical hyperthyroidism a reduction of bone quality may play an important role in determining the increased fracture risk. Indeed, in postmenopausal women treated with suppressive L-thyroxine doses, duration of TSH suppression was negatively correlated with TBS levels, but not with BMD (72). In keeping, vBMD obtained by central QCT showed a more significant correlation with TBS than areal BMD measured by DXA in these patients (73). Similarly, in postmenopausal women treated with TSH-suppressive therapy pQCT showed a significant trabecular bone loss, mainly at non-weight-bearing sites such as the radius (74). Moreover, pQCT did not show differences in terms of vBMD between patients and controls, in premenopausal women, but significant differences were observed in postmenopausal ones. Interestingly, in premenopausal women treated with TSH-suppressive L-thyroxine doses cortical thickness was higher at the radius compared with controls. At variance, in postmenopausal women at radius trabecular bone mineral content, area and vBMD and cortical thickness were reduced (74). Therefore, thyroid hormones excess seems to be associated with a reduction of both cortical and trabecular bone, but only in postmenopausal females.

In addition, the analysis of geometric bone structure properties using HSA showed that in postmenopausal women subclinical hyperthyroidism was associated with a decreased bone strength due to an alteration of bone geometry rather than BMD in the hip area, especially at the femoral neck (75).

In terms of fractures, several studies and metaanalyses have reported an association between subclinical thyroid hormone excess and risk of clinical fractures, mainly in postmenopausal women $(71,76)$. A recent paper showed that about one-third of women treated with TSH-suppressive therapy present at least one vertebral fracture, evaluated by morphometric analysis (77). The presence of vertebral fractures correlated with duration of TSH-suppressive therapy, degree of TSH suppression and age. Interestingly, vertebral fractures were found even in patients with normal BMD, mainly when the TSH level was below $0.5 \mathrm{mU} / \mathrm{L}$.

In conclusion, overt hyperthyroidism is associated with an increased fracture risk in both sexes, which is related to changes in BMD and at least partially reversible using treatment with anti-thyroid drugs. Subclinical hyperthyroidism, both endogenous and exogenous is associated with a higher fracture risk in postmenopausal women, while in premenopausal women and men its possible negative effects remain unclear. In patients with overt hyperthyroidism, DXA may represent a suitable tool to estimate fracture risk. Differently, in subclinical hyperthyroidism BMD changes are not well related with fracture risk, likely due to an impairment of bone quality. In subclinical hyperthyroidism, TBS evaluation may represent a useful and almost easy reachable tool to improve detection of higher risk patients. However, the clinical usefulness of TBS, QCT, pQCT and HAS for the prediction of fracture risk in patients with subclinical hyperthyroidism is still to be demonstrated. Anyway, a vertebral morphometry should be performed in postmenopausal women with subclinical hyperthyroidism; in addition, in patients treated with long-term TSHsuppressive therapy a vertebral morphometry should be repeated during follow-up.

\section{Primary hyperparathyroidism}

In western countries the clinical picture of primary hyperparathyroidism (PHPT) with the devastating effect of very high levels of PTH on bone (i.e. osteitis fibrosa cystica) has become uncommon in the last decades, while the reduction of bone mass and the increased risk of fractures is part of the picture of the commonest mild PHPT. The effects due to the high rate of bone remodelling are well evident at cortical sites. Indeed, the cortical bone is more affected than the trabecular one. In the early 70s, by using old methods, such as metacarpal index, a cortical thinning has been showed in PHPT patients. Since the amount of cortical and trabecular bone varies among different skeletal sites, the common techniques for evaluating bone mass are influenced by the site of measurement. Indeed, bone mass measurement by DXA shows the greatest reduction in BMD at mid- radius, the site of predominantly cortical bone, while at LS, a 
site of predominantly cancellous bone, bone mass can be relatively preserved. At femoral neck a site of mixed composition, BMD is of intermediate value (78). These data have been confirmed by histomorphometric and microcomputed tomography (microCT) studies focused on cohorts of mild PHPT that showed cortical thinning, increased cortical porosity and endocortical trabeculation, but preservation of cancellous bone volume, bone surface and connectivity density of trabecular plates as compared to controls, independent of advancing age (79). These findings suggest that three-dimensional, cancellous bone microarchitecture is preserved in patients with mild PHPT (79). The conservatively follow-up of mild PHPT patients has shown over time a reduction of BMD as evaluated by DXA more evident at sites with prevalent cortical bone, while the surgical treatment, also in mild PHPT, results in increase of BMD by DXA at the distal third radius, femoral neck as well as LS (80). Consequently, BMD evaluation by DXA is mandatory at diagnosis of PHPT and in the follow-up. The risk of fractures (both at spine and femur) is about two fold increased in PHPT and it is reduced by parathyroidectomy (81). Furthermore, in mild PHPT, due to the preservation of trabecular bone, one should not observe any increase of vertebral fractures. In fact, in mild PHPT a higher risk of vertebral fractures was observed, although spine BMD was higher than in controls, thus suggesting that BMD does not seem to be the only factor determining fracture risk in mild PHPT (73), while the impairment of bone microarchitecture and quality (partially evaluated by TBS, HR-pQCT, QUS) could also explain the high risk of fractures. The same results were reported by a subsequent study (82), in which VFA by DXA was utilised for identifying fractures. In this study the accuracy of VFA compared with X-ray was $92 \%$ and sensitivity and specificity of VFA were $82.4 \%$ and $97.0 \%$, respectively. According to the lower mineralisation in PHPT, some phalangeal ultrasound parameters are lower in PHPT than in controls. Phalangeal QUS, seems to evaluate structural characteristics of bone, rather than the mineral content and some QUS parameters would distinguish male and female postmenopausal patients with PHPT from normal controls, but not premenopausal patients (83). However, QUS is not commonly utilised for the characterisation of PHPT patients.

Recent studies showed that TBS appears to be more accurate than spinal BMD for identifying PHPT patients at risk for vertebral fractures (84). Other authors showed that TBS was associated with vertebral fractures regardless of BMD measured at spine, and had a better compromise between sensitivity (75\%) and specificity (61.5\%) for detecting fractured patients than spinal BMD. In surgically treated patients, TBS and spinal BMD increased over time, while in conservatively followed patients, TBS decreased significantly in those with incident vertebral fractures compared with those without, while spinal BMD did not significantly change (85).

By using HR-pQCT in PHPT patients, some authors reported decreased volumetric densities, thinner cortices, and more spaced and not homogeneously distributed trabeculae at trabecular and cortical compartments of distal radius and tibia (86). The individual trabecular segmentation (ITS) analysis of radius, derived from HR-pQCT images, showed reductions in both plate and rod trabecular numbers with plate indexes more affected in respect to controls. At the tibia, the ITS analysis showed that the plate trabecular number and plate bone volume were reduced. A reduction in the plate:rod ratio by $22 \%$ at the radius and $19 \%$ at the tibia, respectively, was observed. Data obtained by HR-pQCT showed that post parathyroidectomy, volumetric BMD, microarchitectural indices and estimated bone strengths improve (86).

\section{Hypercortisolism}

Cushing's syndrome (CS) is a condition characterised by a large group of signs and symptoms that reflect prolonged tissue exposure to glucocorticoid excess of endogenous or exogenous origin. Endogenous cortisol overproduction by the adrenal glands can be due to either adrenocorticotropic hormone excessive secretion (from a pituitary or other ectopic tumour) or autonomous adrenal hyperfunction. Hypercortisolism is a well-known cause of endocrinerelated osteoporosis due to the detrimental effects on bone of cortisol excess, which produces an imbalance between bone resorption (normal or increased, especially in the early phase) and bone formation (impaired, particularly in the chronic phase). This alteration of bone turnover is one of the main mechanisms which leads to bone loss in CS. Many studies investigating bone density in CS patients demonstrated a reduced BMD in these patients (87). Areal BMD, as measured by DXA, was found to be significantly lower in patients with CS than in healthy controls at both the spine and the hip (88) and this reduction was confirmed even after the exclusion of hypogonadal subjects $(88,89)$, thus suggesting that the deleterious effects of hypercortisolism on bone overcome the protective effect of eugonadism in CS. The prevalence of osteoporosis in CS patients varies across studies and can be estimated between 30 and $70 \%(88,89)$. 
The assessment of volumetric BMD, as measured by HR-QCT suggests that the cortisol excess affects more severely trabecular than cortical bone (87), even though some studies were not able to find this difference between these compartments. However, also the microarchitecture of cortical bone is probably injured in CS with lower cortical area and cortical thickness at both the radius and the tibia (88). In a study performed by QCT and pQCT, trabecular, but not cortical and integrated BMD, was significantly reduced in CS patients, suggesting different sensitivities of the two bone tissues to glucocorticoid excess at the forearm (89). In contrast to what observed at the forearm, both trabecular and cortical bone were similarly reduced in CS patients, indicating, therefore, that the different sensitivities to glucocorticoid excess of the two different bone tissues are site specific (i.e. present at the forearm but not at the femur). In addition, by comparing the BMD values for all affected sites in CS patients, spinal trabecular bone, as studied by QCT, was the most severely affected (89).

Data on bone density in CS as assessed by QUS are scarce and quite discordant. Few studies found a reduction of QUS parameters at the phalanges of the non-dominant hand (90) and at the heel (91) in CS patients, whereas others were not able to find any significant bone loss as measured by QUS (92).

However, the bone loss, independent of the technique used for the BMD measurement, does not fully explain the high fracture risk observed in CS. Indeed, approximately $30-67 \%$ of CS patients experienced a clinical fragility fracture in the course of the disease, more commonly at the vertebral level (87) and, as demonstrated by Tauchmanovà and colleagues, this remarkable prevalence of fragility fractures appears to be underestimated, since in about a half of cases vertebral fractures are absolutely asymptomatic. Moreover, in about $10 \%$ of CS patients vertebral fractures occur in the presence of normal BMD (86), thus underlying the crucial role of the radiologic evaluation of the thoracic and LS, regardless of BMD, for the detection of vertebral morphometric fractures. As a consequence SDI has been proposed as a surrogate marker of bone microarchitecture even in CS $(15,93)$.

Indeed, the partial discrepancy between bone mass and fracture risk in CS can be explained by a damage of bone quality other than bone quantity caused by cortisol excess in CS patients. In addition to SDI, TBS has been proposed as another non-invasive technique able to give information on bone microarchitecture. Patients with CS exhibited low TBS values which inversely correlated with the degree of hypercortisolism and which improved more markedly and quickly than BMD after CS remission (94).

A recent work of Maurice and collaborators measured BMF content in CS patients by using MRS, which is considered the best available method for BMF quantification. They found that CS patients had increased BMF content compared to cured patients and healthy subjects (95). However further studies are required in order to clarify the precise link between BMF and bone microarchitecture in hypercortisolism.

It is worthy of attention how imaging evaluation can define skeletal fragility in patients with subclinical hypercortisolism ( $\mathrm{SH})$, which is a condition of cortisol excess in the absence of its classical signs and symptoms (96). As CS, even SH was demonstrated to be detrimental for the bone health, and most studies found a reduction in spinal BMD, as measured by DXA or QCT, in SH patients. At variance, data on femoral BMD in $\mathrm{SH}$ are more discordant (96). However, as compared with CS patients, in $\mathrm{SH}$ patients the degree of BMD loss is even less predictive of the risk of fracture, which is surprisingly comparable with that of CS patients, especially at the vertebral level. This is probably due to a longer exposition to cortisol excess in SH than in CS due to the absence of clinical signs and symptoms (96). As in patients with overt cortisol excess, in $\mathrm{SH}$ an alteration of the bone quality, rather than of bone quantity, is suspected to be the main responsible of the skeletal fragility (92) and TBS was found to be reduced in $\mathrm{SH}$ patients and correlated with the number and severity of vertebral fractures and with the degree of cortisol excess (97).

\section{Hypogonadism}

Bone health is a major concern in patients with hypogonadism. Oestrogen levels lower than 20 pg/ $\mathrm{mL}$ are associated with significant bone loss and levels below $5 \mathrm{pg} / \mathrm{ml}$ are associated with a 2.5 -fold increase in hip and vertebral fractures independently of sex, age and body weight (98). In male hypogonadism, the BMD values associated to fracture risk are not so well defined as in postmenopausal women or glucocorticoid-induced osteoporosis. In hypogonadism the rate of bone loss is increased due to a very high bone turnover. This, in turn, decreases bone quality and increases the fracture risk partially independently of BMD reduction (99). Indeed, a high bone turnover impairs bone strength in excess that expected from the change in bone mass. 
All acquired hypogonadisms, in particular in young age or if occur quickly (i.e. surgical or pharmacological castration) are associated with a very high bone turnover. The hormonal ablation for cancer adjuvant therapy or for endometriosis is the best studied secondary osteoporosis due to hypogonadism. Gonadotrophinreleasing hormone agonists or analogues are used in prostate cancer, premenopausal breast cancer women and endometriosis. Furthermore aromatase inhibitors nowadays are the standard of adjuvant therapy in oestrogen receptor positive postmenopausal breast cancer (100). Bone loss in these patients, begin early after the beginning of hormonal therapy and progresses with high rate (100).

There are strong evidences that in the cancer treatmentinduced bone loss (CTIBL) as well as young women with endometriosis there is a very compromised bone quality with lower trabecular volume, fewer trabeculae number, higher trabecular interruption and cortical porosity than in controls as evaluated by HR-pQCT (101, 102, 103). The fracture incidence in patients with breast cancer treated with aromatase inhibitors was $7-26 \%$ at 7 years of treatment (104), and about 23-28\% in patients with prostate cancer on antiandrogen therapy (105). Overall the fractures occur very precociously after the start of hormonal ablation, when BMD is often not impaired $(104,106)$. The increased awareness about CTIBL has led to guidelines and expert panel to recommend to monitor for bone loss with BMD by DXA (107). However in a retrospective study on 17,110 breast cancer survivor followed about 5 years demonstrated that the increased risk of a fracture was not explained by worse BMD suggesting that BMD does not adequately capture bone strength determinants as shown in other studies (108). When postmenopausal women with breast cancer treated with aromatase inhibitors were randomised to receive placebo or denosumab, the risk of all fracture in placebo group and the risk of fracture reduction in denosumab group were substantially independent of BMD (104). Interestingly, in patients with prostate cancer the fracture risk is better expressed by calculating FRAX without BMD than with BMD (109).

In keeping with the idea that that skeletal fragility is prominently dependent on the poor quality of bone microarchitecture, in In patients with breast cancer treated with exemestane, TBS significantly decreases of $2.3 \%$ and BMD of $5 \%$ in 24 months of treatment and in particular the changes were independent from each other (110). In a retrospective longitudinal study in breast cancer patients treated with aromatase inhibitors for more than 3 years, along with an impairment of bone quality parameters, TBS also significantly decreased from baseline to 5 years $(2.1 \%)$ and this change remained significant after adjusting for LS BMD (111). In B-ABLE study TBS and BMD significantly decreased in not treated patients with breast cancer, while in bisphosphonates treated subjects BMD increased and TBS remained stable at the end of the treatment with aromatase inhibitors. In both groups the changes in spine BMD and TBS were weakly correlated (112). Similar results were found in premenopausal breast cancer women treated with zoledronic acid (113). Therefore, TBS could be suitable to improve the fracture risk definition in CTIBL patients and could be usefully combined with FRAX and BMD to maximise the identification of patients with elevated risk (114).

In the future, other technologies that capture a combination of bone mass and bone quality and the possibility to assess the separate role of trabecular and cortical bone could potentially be useful for fracture risk definition in CTIBL besides DXA. Indeed, MRI of trabecular microarchitecture actually refers to imaging of the marrow contents of the trabecular bone tissue compartment. These studies were performed with 1.5T, 3T and 7T MRI. Cortical bone is an important contributor to bone strength as evidenced by recent data using MRI. Cortical bone has a very short $\mathrm{T} 2$ relaxation times $(<1 \mathrm{~ms})$ and, using a very short or ultra-short echo, cortical bone porosity and collagen-bound water could be captured. The available in vivo clinical studies are so far very few (115).

In patients with prostate cancer on androgen deprivation therapy, with vertebral fracture MRI demonstrated bone quality deterioration at distal radius compared to controls and the addition of these parameters to BMD significantly improves the ability to individuate fractured patients (115). Even pQCT is available method to quantify separately cortical and trabecular bone at peripheral skeletal site. In breast cancer patients on hormonal adjuvant therapy pQCT surprisingly demonstrated a prominent negative impact of anastrozole on cortical bone as compared with healthy control women (104).

Recentlyalso ancillary analyses of PET-CT examinations were compared against values obtained using routine multidetector-row computed tomography (MDCT) with promising performances (116). However, to date, there are not strong evidences that microarchitecture definition by MRI, MDCT or QCT could become the standard methods to assess the risk of fractures in hypogonadal subjects. It is 
likely that a combination of different technologies should offer the best definition of bone strength but also the costeffectiveness of this approach should be determined.

\section{Fracture risk assessment in secondary osteoporosis}

In many conditions other than postmenopausal osteoporosis the fracture risk is neglected or underestimated and the use of an algorithm represents the solution to ensure a homogeneous evaluation among specialists and an appropriate approach to therapy. The most commonly used is FRAX® that calculates absolute fracture probability from ten easily obtained risk factors in optional conjunction with BMD T-score values (117). Among the risk factors 'secondary osteoporosis' is included, which encompasses namely: type 1 diabetes, osteogenesis imperfecta in adults, untreated longstanding hyperthyroidism, hypogonadism or premature menopause (before 45 years), chronic malnutrition and chronic liver disease. Many other well-known conditions associated to bone fragility, such as hyperparathyroidism, T2DM, obesity, cancer and hormonal adjuvant therapy, HIV, chronic inflammatory bowel disease and obstructive respiratory disease are not included (https://www. sheffield.ac.uk/FRAX, last access 02.12.2019), although they have been very recently re-evaluated (118).

Endogenous hypercortisolism is not formally included but the term 'glucocorticoid' is among the ten risk factors and in the place of the term 'obesity' the term 'BMI' is present. Moreover, FRAX calculation has been included in some International Guidelines as IOF/ECTS, ESCEO and American College of Rheumatology for the management of glucocorticoid osteoporosis and CITBL in breast and prostate cancer $(119,120,121)$.

However, FRAX has been designed to assess fracture risk in postmenopausal osteoporosis which substantially differs as compared with the condition of bone fragility due to endocrine disorders. Indeed, in these latter conditions, bone microarchitecture alterations and/or other factors (as for example the risk of fall) are crucial determinant of the fracture risk. Therefore, in these condition the DXA values may substantially underestimate the risk of fracture $(4,43,84,85,122,123)$. This explains why in these condition the 'secondary osteoporosis' option in the FRAX tool has a much smaller effect on fracture risk than would be expected, and it has been suggested to use the bypass of rheumatoid arthritis in the FRAX tool to correct the estimation of fracture risk (122). Moreover, since BMD in many conditions is not impaired or it is even higher than expected $(4,43,84,85,122,123)$, the fracture risk prediction by FRAX may be improved by excluding BMD in the algorithm computation $(4,124,125,126)$ or by downward adjusting BMD by 0.5 standard deviation (39). Finally the TBS-adjusted FRAX, being TBS an independent fracture risk capturing 'quality' aspects of bone structure, has suggested to possibly improve the absolute fracture risk definition in secondary osteoporosis $(114,127,128)$.

In conclusion for the absolute fracture risk assessment in the majority of secondary osteoporosis FRAX is currently not performing as in postmenopausal osteoporosis and the 'secondary osteoporosis' option does not adequately correct the underestimation of the fracture risk. Excluding BMD, or including 'Arthritis Rheumatism' or TBS could currently be options to improve the fracture risk predictability using FRAX in secondary osteoporosis. As suggest in the update of the European Guidelines for osteoporosis imminent new FRAX version could be take in account these needs for the management of secondary osteoporosis (118).

\section{Conclusions and perspectives}

In the present review we have summarised the available data about the imaging tools that can be used in evaluating the fracture risk in patients with the most common endocrine forms of osteoporosis and bone fragility. A summary of the main characteristics of the different noninvasive imaging methods for the assessment of bone health is reported in Table 4.

It is possible, however, that even in healthy subjects, the endocrine milieu (in term of degree of secretion, peripheral activation and sensitivity) could play a role in predisposing to fracture risk. Indeed, cortisol levels seems to be associated with BMD in women with postmenopausal osteoporosis $(129,130)$, the activity of the 11ß-hydroxysteroid dehydrogenase shuttle, which regulates the glucocorticoid peripheral activity, seems to influence the risk of vertebral fractures $(131,132)$, and the different GC receptor polymorphisms, have been suggested to be associated with the fracture risk in patients with no evidence of cortisol excess $(133,134)$. Furthermore, recent data show that even in primary aldosteronism femur and spine BMD and TBS are reduced $(135,136)$ and that the fracture risk is increased $(137,138)$. This clinical picture as well as fracture risk recedes after treatment, particularly after surgery (139). Since aldosterone secretion is increased in a large part of hypertensive patients (139), altogether 
Table 4 Summary and main characteristics of the different non-invasive imaging methods for the assessment of bone health.

\begin{tabular}{|c|c|c|}
\hline Imaging method & $\begin{array}{l}\text { Parameters } \\
\text { assessed }\end{array}$ & Skeletal site \\
\hline DXA & Areal BMD & $\begin{array}{l}\text { Lumbar spine, hip, } \\
\text { radius, total body }\end{array}$ \\
\hline TBS & $\begin{array}{l}\text { Pixel grey-level } \\
\text { texture }\end{array}$ & Lumbar spine \\
\hline VFA & Vertebral fractures & $\begin{array}{l}\text { Thoracolumbar } \\
\text { spine }\end{array}$ \\
\hline HSA & Hip bone geometry & Hip \\
\hline $\begin{array}{l}\text { Conventional } \\
\text { radiography } \\
\text { (X-ray) }\end{array}$ & $\begin{array}{l}\text { Morphometric } \\
\text { vertebral } \\
\text { fractures }\end{array}$ & $\begin{array}{l}\text { Thoracolumbar } \\
\text { spine }\end{array}$ \\
\hline QUS & $\begin{array}{l}\text { SOS, BUA and } \\
\text { other derived } \\
\text { parameters }\end{array}$ & $\begin{array}{l}\text { Heel, phalanges of } \\
\text { the non-dominant } \\
\text { hand }\end{array}$ \\
\hline $\begin{array}{l}\text { QCT-based } \\
\text { methods }\end{array}$ & Volumetric BMD & $\begin{array}{l}\text { Distal radius, tibia } \\
\quad(\mathrm{HR}-\mathrm{pQCT}) \\
\text { Spine (central QCT) }\end{array}$ \\
\hline $\begin{array}{l}\text { MRI-based } \\
\text { methods }\end{array}$ & $\begin{array}{l}\text { Bone } \\
\text { microstructure }\end{array}$ & $\begin{array}{l}\text { Peripheral skeletal } \\
\text { sites (HR-MRI) } \\
\text { Spine (MRS) }\end{array}$ \\
\hline
\end{tabular}

\section{Clinical and research applications}

WHO diagnosis of osteoporosis, input for FRAX, body composition evaluation

Index of trabecular bone quality, improvement of FRAX prediction

Detection of vertebral fractures by using DXA image (sensitivity and specificity $>90 \%$ for moderate and severe fractures)

Evaluation of hip bone strength

Detection of morphometric vertebral fractures, SDI calculation

Indirect quantification of bone tissue properties and BMD without ionising radiation exposure

Assessment of cortical and trabecular bone compartments, QCT-derived FEA modelling for bone strength estimation

Assessment of bone microarchitecture, MRIderived FEA modelling for bone strength estimation (HR-MRI)

BMF evaluation (MRS)

$\mathrm{BMD}$, bone mineral density; BMF, bone marrow fat; BUA, broadband ultrasound attenuation; DXA, dual-X-ray absorptiometry; FEA, finite element analysis; HR-MRI, high-resolution magnetic resonance imaging; HR-pQCT, high-resolution peripheral quantitative computed tomography; HSA, hip structural analysis (DXA-based method); MRI, magnetic resonance imaging; MRS, magnetic resonance spectroscopy; QCT, quantitative computed tomography; QUS, quantitative ultrasound; SDI, spinal deformity index; SOS, ultrasound speed of sound; TBS, trabecular bone score (DXA-based measurement); VFA, vertebral fracture assessment (DXA-based method).

these data may suggest that cortisol and aldosterone secretion may represent two so far ignored contributors to osteoporosis in the general population.

The issue of hypovitaminosis $\mathrm{D}$ and of secondary hyperparathyroidism as possible endocrine causes of bone fragility was beyond the scope of the present review. However, it is important to underline that hypovitaminosis may be a potential contributor to bone fragility in all forms of secondary osteoporosis and may influence their diagnostic work-up. Indeed in up to 30\% of cases, the diagnosis of PHPT may be missed if the biochemical work-up is performed in the presence of low vitamin D levels (2). Besides hypovitaminosis D, a concomitant mineralisation disorder, impacting on bone density and quality could influence the effect of an endocrine disease on bone fragility $(140,141)$. Therefore, in all endocrinerelated forms of bone fragility, the vitamin $\mathrm{D}$ status has to be assessed and the presence of a mineralisation disorder has to be excluded.

Finally, a limit of many studies assessing bone fragility in the endocrine disorders is related to the clinical significance of morphometric vertebral fractures. Indeed, in all studies cited in the presence review the morphometric vertebral fractures were defined as at least a $20 \%$ deformity (i.e. at least I grade). However, the significance and predictive ability of grade I vertebral fractures for future fractures is still questioned (142).

In conclusion, the endocrine-related forms of osteoporosis are characterised by an increased risk of fracture, which is often hardly predictable by DXA. Even though TBS seems to be useful for assessing the fracture risk in patients affect with an endocrine disease, further studies are needed. In particular, TBS is incapable of directly assessing osseous microarchitecture and the overall effect 
of the joint use of TBS with FRAX is modest, with most of its clinical impact limited to patients already close to an intervention threshold. Moreover, in some studies TBS did not improve ROC curves on fracture risk over femur BMD alone. Finally, to date, we have no sufficient evidence suggesting that TBS can be used to assess the effect of pharmacologic anti-fracture treatment (143).

Hopefully, in the future, new imaging methods for evaluating both bone density and quality could be introduced in the clinical practice. This would help to better identify patients with endocrine diseases at high risk of fracture, therefore consenting their early treatment. These methods could even consent to evaluate the effect of the drug therapy and medical rehabilitation on the skeletal health in patients affected with an endocrinerelated form of bone fragility.

\section{Declaration of interest}

The authors declare that there is no conflict of interest that could be perceived as prejudicing the impartiality of this review.

\section{Funding}

This research has been partially supported by the Research Grant GLPBONE 2019_01_29_07 by Istituto Auxologico Italiano.

\section{References}

1 Mirza F \& Canalis E. Management of endocrine disease: secondary osteoporosis: pathophysiology and management. European Journal of Endocrinology 2015173 R131-R151. (https://doi.org/10.1530/EJE-150118)

2 Eller-Vainicher C, Cairoli E, Zhukouskaya VV, Morelli V, Palmieri S, Scillitani A, Beck-Peccoz P \& Chiodini I. Prevalence of subclinical contributors to low bone mineral density and/or fragility fracture. European Journal of Endocrinology 2013169 225-237. (https://doi. org/10.1530/EJE-13-0102)

3 Compston JE, Flahive J, Hooven FH, Anderson FA Jr, Adachi JD, Boonen S, Chapurlat RD, Cooper C, Díez-Perez A, Greenspan SL et al. Obesity, health-care utilization, and health-related quality of life after fracture in postmenopausal women: global longitudinal study of osteoporosis in women (GLOW). Calcified Tissue International 2014 94 223-231. (https://doi.org/10.1007/s00223-013-9801-z)

4 Walsh JS \& Vilaca T. Obesity, type 2 diabetes and bone in adults. Calcified Tissue International 2017100 528-535. (https://doi. org/10.1007/s00223-016-0229-0)

5 Folsom AR, Kushi LH, Anderson KE, Mink PJ, Olson JE, Hong CP, Sellers TA, Lazovich D \& Prineas RJ. Associations of general and abdominal obesity with multiple health outcomes in older women: the Iowa women's health study. Archives of Internal Medicine 2000 160 2117-2128. (https://doi.org/10.1001/archinte.160.14.2117) 6 Machado LG, Domiciano DS, Figueiredo CP, Caparbo VF, Takayama L, Oliveira RM, Lopes JB, Menezes PR \& Pereira RM. Visceral fat measured by DXA is associated with increased risk of non-spine fractures in nonobese elderly women: a population-based prospective cohort analysis from the Sao Paulo Ageing \& Health (SPAH) study. Osteoporosis International 201627 3525-3533. (https:// doi.org/10.1007/s00198-016-3682-8)
7 Sadeghi O, Saneei P, Nasiri M, Larijani B \& Esmaillzadeh A. Abdominal obesity and risk of hip fracture: a systematic review and meta-analysis of prospective studies. Advances in Nutrition 20178 728-738. (https://doi.org/10.3945/an.117.015545)

8 Fassio A, Idolazzi L, Rossini M, Gatti D, Adami G, Giollo A \& Viapiana O. The obesity paradox and osteoporosis. Eating and Weight Disorders 201823 293-302. (https://doi.org/10.1007/s40519-0180505-2)

9 Chang CS, Chang YF, Wang MW, Chen CY, Chao YJ, Chang HJ, Kuo PH, Yang YC \& Wu CH. Inverse relationship between central obesity and osteoporosis in osteoporotic drug naive elderly females: the Tianliao Old People (TOP) Study. Journal of Clinical Densitometry 201316 204-211. (https://doi.org/10.1016/j.jocd.2012.03.008)

10 Ruosi C, Liccardo S, Rubino M, Colella G, Di Somma C \& Colao A. Importance of spinal deformity index in risk evaluation of VCF (vertebral compression fractures) in obese subjects: prospective study. European Spine Journal 201322 (Supplement 6) S945-S949. (https:// doi.org/10.1007/s00586-013-3009-9)

11 Huang HL, Pan CC, Hsiao YF, Chen MC, Kung CY, Kung PT \& Tsai WC. Associations of body mass index and diabetes with hip fracture risk: a nationwide cohort study. BMC Public Health 201818 1325. (https://doi.org/10.1186/s12889-018-6230-y)

12 Shepherd JA, Schousboe JT, Broy SB, Engelke K \& Leslie WD. Executive summary of the 2015 ISCD position development conference on advanced measures From DXA and QCT: fracture prediction Beyond BMD. Journal of Clinical Densitometry 201518 274-286. (https://doi.org/10.1016/j.jocd.2015.06.013)

13 Romagnoli E, Lubrano C, Carnevale V, Costantini D, Nieddu L, Morano S, Migliaccio S, Gnessi L \& Lenzi A. Assessment of trabecular bone score (TBS) in overweight/obese men: effect of metabolic and anthropometric factors. Endocrine 201654 342-347. (https://doi. org/10.1007/s12020-016-0857-1)

14 Marengo AP, Guerrero Pérez F, San Martín L, Monseny R, Casajoana A, Valera R, Virgili N, Simó Servat A, Prats A, GómezVaquero $\mathrm{C}$ et al. Is trabecular bone score valuable in bone microstructure assessment after gastric bypass in women with morbid obesity? Nutrients 20179 E1314-E1324. (https://doi. org/10.3390/nu9121314)

15 Kerkeni S, Kolta S, Fechtenbaum J \& Roux C. Spinal deformity index (SDI) is a good predictor of incident vertebral fractures. Osteoporosis International 200920 1547-1552. (https://doi.org/10.1007/s00198008-0832-7)

16 Kuet KP, Charlesworth D \& Peel NFA. Vertebral fracture assessment scans enhance targeting of investigations and treatment within a fracture risk assessment pathway. Osteoporosis International 201324 1007-1014. (https://doi.org/10.1007/s00198-012-2255-8)

17 Puisto V, Heliövaara M, Impivaara O, Jalanko T, Kröger H, Knekt P, Aromaa A, Rissanen H \& Helenius I. Severity of vertebral fracture and risk of hip fracture: a nested case-control study. Osteoporosis International 201122 63-68. (https://doi.org/10.1007/s00198-0101195-4)

18 Fazeli PK, Horowitz MC, MacDougald OA, Scheller EL, Rodeheffer MS, Rosen CJ \& Klibanski A. Marrow fat and bone - new perspectives. Journal of Clinical Endocrinology and Metabolism 201398 935-945. (https://doi.org/10.1210/jc.2012-3634)

19 Devlin MJ \& Rosen CJ. The bone-fat interface: basic and clinical implications of marrow adiposity. Lancet: Diabetes and Endocrinology 20153 141-147. (https://doi.org/10.1016/S2213-8587(14)70007-5)

20 Cordes C, Baum T, Dieckmeyer M, Ruschke S, Diefenbach MN, Hauner H \& Kirschke JS \& Karampinos DC. MR-based assessment of bone marrow fat in osteoporosis. Diabetes, and obesity. Frontiers in Endocrinology 201674 1-7. (https://doi.org/10.3389/ fendo.2016.00074)

21 Baum T, Yap SP, Karampinos DC, Nardo L, Kuo D, Burghardt AJ, Masharani UB, Schwartz AV, Li X \& Link TM. Does vertebral bone marrow fat content correlate with abdominal adipose tissue, lumbar 
spine bone mineral density, and blood biomarkers in women with type 2 diabetes mellitus? Journal of Magnetic Resonance Imaging 2012 35 117-124. (https://doi.org/10.1002/jmri.22757)

22 Cohen A, Shen W, Dempster DW, Zhou H, Recker RR, Lappe JM, Kepley A, Kamanda-Kosseh M, Bucovsky M, Stein EM et al. Marrow adiposity assessed on transiliac crest biopsy samples correlates with noninvasive measurement of marrow adiposity by proton magnetic resonance spectroscopy (1H-MRS) at the spine but not the femur. Osteoporosis International 201526 2471-2478. (https://doi org/10.1007/s00198-015-3161-7)

23 Karampinos DC, Ruschke S, Gordijenko O, Grande Garcia E, Kooijman H, Burgkart R, Rummeny EJ, Bauer JS \& Baum T. Association of MRS-based vertebral bone marrow fat fraction with bone strength in a human in vitro model. Journal of Osteoporosis 2015 2015 152349. doi:10.1155/2015/152349.

24 Schafer AL, Li X, Schwartz AV, Tufts LS, Wheeler AL, Grunfeld C, Stewart L, Rogers SJ, Carter JT, Posselt AM et al. Changes in vertebral bone marrow fat and bone mass after gastric bypass surgery: a pilot study. Bone 201574 140-145. (https://doi.org/10.1016/j. bone.2015.01.010)

25 Yeung DK, Griffith JF, Antonio GE, Lee FK, Woo J \& Leung PC. Osteoporosis is associated with increased marrow fat content and decreased marrow fat unsaturation: a proton MR spectroscopy study. Journal of Magnetic Resonance Imaging 200522 279-285. (https://doi. org/10.1002/jmri.20367)

26 Scheller EL \& Rosen CJ. What's the matter with MAT? Marrow adipose tissue, metabolism, and skeletal health. Annals of the New York Academy of Sciences 20141311 14-30. (https://doi.org/10.1111/ nyas.12327)

27 Bredella MA, Gerweck AV, Barber LA, Breggia A, Rosen CJ, Torriani M $\&$ Miller KK. Effects of growth hormone administration for 6 months on bone turnover and bone marrow fat in obese premenopausal women. Bone 201462 29-35. (https://doi.org/10.1016/j. bone.2014.01.022)

28 Bredella MA, Torriani M, Ghomi RH, Thomas BJ, Brick DJ, Gerweck AV, Rosen CJ, Klibanski A \& Miller KK. Vertebral bone marrow fat is positively associated with visceral fat and inversely associated with IGF-1 in obese women. Obesity 201119 49-53. (https://doi.org/10.1038/oby.2010.106)

29 Gagnon C \& Schafer AL. Bone health after bariatric surgery. Journal of Bone and Mineral Research 20182 121-133. (https://doi.org/10.1002/ jbm4.10048)

30 Stein EM, Carrelli A, Young P, Bucovsky M, Zhang C, Schrope B, Bessler M, Zhou B, Wang J, Guo XE et al. Bariatric surgery results in cortical bone loss. Journal of Clinical Endocrinology and Metabolism 201398 541-549. (https://doi.org/10.1210/jc.2012-2394)

31 Yu EW, Bouxsein ML, Putman MS, Monis EL, Roy AE, Pratt JS, Butsch WS \& Finkelstein JS. Two-year changes in bone density after Roux-en-Y gastric bypass surgery. Journal of Clinical Endocrinology and Metabolism 2015100 1452-1459. (https://doi.org/10.1210/jc.20144341)

32 Crawford MR, Pham N, Khan L, Bena JF, Schauer PR \& Kashyap SR. Increased bone turnover in type 2 diabetes patients randomized to bariatric surgery vs. medical therapy at least 5 years. Endocrine Practice 201824 256-264. (https://doi.org/10.4158/EP-2017-0072)

33 Shanbhogue VV, Støving RK, Frederiksen KH, Hanson S, Brixen K, Gram J, Jørgensen NR \& Hansen S. Bone structural changes after gastric bypass surgery evaluated by HR-pQCT: a two year longitudinal study. European Journal of Endocrinology 2017176 685-693. (https:// doi.org/10.1530/EJE-17-0014)

34 Bredella MA, Greenblatt LB, Eajazi A, Torriani M \& Yu EW. Effects of Roux-en-Y gastric bypass and sleeve gastrectomy on bone mineral density and marrow adipose tissue. Bone 201795 85-90. (https://doi. org/10.1016/j.bone.2016.11.014)

35 Ivaska KK, Huovinen V, Soinio M, Hannukainen JC, Saunavaara V, Salminen P, Helmiö M, Parkkola R, Nuutila P \& Kiviranta R. Changes in bone metabolism after bariatric surgery by gastric bypass or sleeve gastrectomy. Bone 201795 47-54. (https://doi.org/10.1016/j. bone.2016.11.001)

36 Merlotti D, Gennari L, Dotta F, Lauro D \& Nuti R. Mechanisms of impaired bone strength in type 1 and 2 diabetes. Nutrition, Metabolism, and Cardiovascular Diseases 201020 683-690. (https:// doi.org/10.1016/j.numecd.2010.07.008)

37 Vestergaard P. Discrepancies in bone mineral density and fracture risk in patients with type 1 and type 2 diabetes - a meta-analysis. Osteoporosis International 200718 427-444. (https://doi.org/10.1007/ s00198-006-0253-4)

38 Hofbauer LC, Brueck CC, Singh SK \& Dobnig H. Osteoporosis in patients with diabetes mellitus. Journal of Bone and Mineral Research 200722 1317-1328. (https://doi.org/10.1359/jbmr.070510)

39 Schacter GI \& Leslie WD. DXA-based measurements in diabetes: can they predict fracture risk? Calcified Tissue International $2017 \mathbf{1 0 0}$ 150-164. (https://doi.org/10.1007/s00223-016-0191-x)

40 Schwartz AV, Vittinghoff E, Bauer DC, Hillier TA, Strotmeyer ES, Ensrud KE, Donaldson MG, Cauley JA, Harris TB, Koster A et al. Association of BMD and FRAX score with risk of fracture in older adults with type 2 diabetes. JAMA 2011305 2184-2192. (https://doi. org/10.1001/jama.2011.715)

41 Carnevale V, Morano S, Fontana A, Annese MA, Fallarino M, Filardi T, Copetti M, Pellegrini F, Romagnoli E, Eller-Vainicher C et al. Assessment of fracture risk by the FRAX algorithm in men and women with and without type 2 diabetes mellitus: a cross-sectional study. Diabetes/Metabolism Research and Reviews 201430 313-322. (https://doi.org/10.1002/dmrr.2497)

42 Zhukouskaya VV, Eller-Vainicher C, Gaudio A, Cairoli E, Ulivieri FM, Palmieri S, Morelli V, Orsi E, Masserini B, Barbieri AM et al. In postmenopausal female subjects with type 2 diabetes mellitus, vertebral fractures are independently associated with cortisol secretion and sensitivity. Journal of Clinical Endocrinology and Metabolism 2015100 1417-1425. (https://doi.org/10.1210/jc.20144177)

43 Poiana C \& Capatina C. Fracture risk assessment in patients with diabetes mellitus. Journal of Clinical Densitometry 201720 432-443. (https://doi.org/10.1016/j.jocd.2017.06.011)

44 Jiang N \& Xia W. Assessment of bone quality in patients with diabetes mellitus. Osteoporosis International 201829 1721-1736. (https://doi.org/10.1007/s00198-018-4532-7)

45 Leslie WD, Aubry-Rozier B, Lamy O \& Hans D. TBS (trabecular bone score) and diabetes-related fracture risk. Journal of Clinical Endocrinology and Metabolism 201398 602-609. (https://doi. org/10.1210/jc.2012-3118)

46 Zhukouskaya VV, Eller-Vainicher C, Gaudio A, Privitera F, Cairoli E, Ulivieri FM, Palmieri S, Morelli V, Grancini V, Orsi E et al. The utility of lumbar spine trabecular bone score and femoral neck bone mineral density for identifying asymptomatic vertebral fractures in well-compensated type 2 diabetic patients. Osteoporosis International 201627 49-56. (https://doi.org/10.1007/s00198-015-3212-0)

47 Bonnick SL. HSA: beyond BMD with DXA. Bone 200741 S9-S12. (https://doi.org/10.1016/j.bone.2007.03.007)

48 Chobot AP, Haffke A, Polanska J, Halaba ZP, Deja G, Jarosz-Chobot P \& Pluskiewicz W. Bone status in adolescents with type 1 diabetes. Diabetologia 201053 1754-1760. (https://doi.org/10.1007/s00125010-1782-0)

49 Yamaguchi T, Yamamoto M, Kanazawa I, Yamauchi M, Yano S, Tanaka N, Nitta E, Fukuma A, Uno S, Sho-no T et al. Quantitative ultrasound and vertebral fractures in patients with type 2 diabetes. Journal of Bone and Mineral Metabolism 201129 626-632. (https://doi. org/10.1007/s00774-011-0265-9)

50 Conti F, Balducci S, Pugliese L, D'Errico V, Vitale M, Alessi E, Salerno G, Iacobini C, Menini S, Bollanti L et al. Correlates of calcaneal quantitative ultrasound parameters in patients with diabetes: the study on the assessment of determinants of muscle and 
bone strength abnormalities in diabetes. Journal of Diabetes Research 20172017 1-12. (https://doi.org/10.1155/2017/4749619)

51 Shah VN, Carpenter RD, Ferguson VL \& Schwartz AV. Bone health in type 1 diabetes. Current Opinion in Endocrinology, Diabetes, and Obesity 201825 231-236. (https://doi.org/10.1097/ MED.0000000000000421)

52 Shanbhogue VV, Hansen S, Frost M, Jorgensen NR, Hermann AP, Henriksen JE \& Brixen K. Bone geometry, volumetric density, microarchitecture, and estimated bone strength assessed by HR-pQCT in adult patients with type 1 diabetes mellitus. Journal of Bone and Mineral Research 201530 2188-2199. (https://doi. org/10.1002/jbmr.2573)

53 Patsch JM, Burghardt AJ, Yap SP, Baum T, Schwartz AV, Joseph GB $\&$ Link TM. Increased cortical porosity in type 2 diabetic postmenopausal women with fragility fractures. Journal of Bone and Mineral Research 201328 313-324. (https://doi.org/10.1002/ jbmr.1763)

54 Yu EW, Putman MS, Derrico N, Abrishamanian-Garcia G, Finkelstein JS \& Bouxsein ML. Defects in cortical microarchitecture among African-American women with type 2 diabetes. Osteoporosis International 201526 673-679. (https://doi.org/10.1007/s00198-0142927-7)

55 Osima M, Kral R, Borgen TT, Høgestøl IK, Joakimsen RM, Eriksen EF \& Bjørnerem Å. Women with type 2 diabetes mellitus have lower cortical porosity of the proximal femoral shaft using low-resolution $\mathrm{CT}$ than nondiabetic women, and increasing glucose is associated with reduced cortical porosity. Bone 201797 252-260. (https://doi. org/10.1016/j.bone.2017.01.037)

56 Samelson EJ, Demissie S, Cupples LA, Zhang X, Xu H, Liu CT, Boyd SK, McLean RR, Broe KE, Kiel DP et al. Diabetes and deficits in cortical bone density microarchitecture, and bone size: Framingham HR-pQCT study. Journal of Bone and Mineral Research 201833 54-62. (https://doi.org/10.1002/jbmr.3240)

57 Mazziotti G, Frara S \& Giustina A. Pituitary diseases and bone. Endocrine Reviews 201839 440-488. (https://doi.org/10.1210/er.201800005)

58 Dalle Carbonare L, Micheletti V, Cosaro E, Valenti MT, Mottes M, Francia G \& Davì MV. Bone histomorphometry in acromegaly patients with fragility vertebral fractures. Pituitary 201821 56-64. (https://doi.org/10.1007/s11102-017-0847-1)

59 Hong AR, Kim JH, Kim SW, Kim SY \& Shin CS. Trabecular bone score as a skeletal fragility index in acromegaly patients. Osteoporosis International 201627 1123-1129. (https://doi.org/10.1007/s00198015-3344-2)

60 Godang K, Olarescu NC, Bollerslev J \& Heck A. Treatment of acromegaly increases BMD but reduces trabecular bone score: a longitudinal study. European Journal of Endocrinology $2016 \mathbf{1 7 5}$ 155-164. (https://doi.org/10.1530/EJE-16-0340)

61 Madeira M, Neto LV, de Paula Paranhos Neto F, Barbosa Lima IC, Carvalho de Mendonça LM, Gadelha MR \& Fleiuss de Farias ML. Acromegaly has a negative influence on trabecular bone, but not on cortical bone, as assessed by high-resolution peripheral quantitative computed tomography. Journal of Clinical Endocrinology and Metabolism 201398 1734-1741. (https://doi.org/10.1210/jc.20124073)

62 Scillitani A, Chiodini I, Carnevale V, Giannatempo GM, Frusciante V, Villella M, Pileri M, Guglielmi G, Di Giorgio A, Modoni S et al. Skeletal involvement in female acromegalic subjects: the effects of growth hormone excess in amenorrheal and menstruating patients. Journal of Bone and Mineral Research 199712 1729-1736. (https://doi. org/10.1359/jbmr.1997.12.10.1729)

63 Silva PPB, Amlashi FG, Yu EW, Pulaski-Liebert KJ, Gerweck AV, Fazeli PK, Lawson E, Nachtigall LB, Biller BMK, Miller KK et al. Bone microarchitecture and estimated bone strength in men with active acromegaly. European Journal of Endocrinology 2017177 409-420. (https://doi.org/10.1530/EJE-17-0468)
64 Malgo F, Hamdy NAT, Rabelink TJ, Kroon HM, Claessen KMJA, Pereira AM, Biermasz NR \& Appelman-Dijkstra NM. Bone material strength index as measured by impact microindentation is altered in patients with acromegaly. European Journal of Endocrinology 2017176 339-347. (https://doi.org/10.1530/EJE-16-0808)

65 Maffezzoni F, Maddalo M, Frara S, Mezzone M, Zorza I, Baruffaldi F, Doglietto F, Mazziotti G, Maroldi R \& Giustina A. High-resolutioncone beam tomography analysis of bone microarchitecture in patients with acromegaly and radiological vertebral fractures. Endocrine 201654 532-542. (https://doi.org/10.1007/s12020-0161078-3)

66 Mazziotti G, Biagioli E, Maffezzoni F, Spinello M, Serra V, Maroldi R, Floriani I \& Giustina A. Bone turnover, bone mineral density, and fracture risk in acromegaly: a meta-analysis. Journal of Clinical Endocrinology and Metabolism 2015100 384-394. (https://doi. org/10.1210/jc.2014-2937)

67 Williams GR \& Bassett JHD. Thyroid diseases and bone health. Journal of Endocrinological Investigation 201841 99-109. (https://doi. org/10.1007/s40618-017-0753-4)

68 Bassett JHD \& Williams GR. Role of thyroid hormones in skeletal development and bone maintenance. Endocrine Reviews 201637 135-187. (https://doi.org/10.1210/er.2015-1106)

69 Vestergaard P \& Mosekilde L. Hyperthyroidism, bone mineral, and fracture risk - a meta-analysis. Thyroid 200313 585-593. (https://doi. org/10.1089/105072503322238854)

70 Segna D, Bauer DC, Feller M, Schneider C, Fink HA, Aubert CE, Collet TH, da Costa BR, Fischer K, Peeters RP et al. Association between subclinical thyroid dysfunction and change in bone mineral density in prospective cohorts. Journal of Internal Medicine 2018283 56-72. (https://doi.org/10.1111/joim.12688)

71 Yan Z, Huang H, Li J \& Wang J. Relationship between subclinical thyroid dysfunction and the risk of fracture: a meta-analysis of prospective cohort studies. Osteoporosis International 201627 115-125. (https://doi.org/10.1007/s00198-015-3221-z)

72 Moon JH, Kim KM, Oh TJ, Choi SH, Lim S, Park YJ, Park DJ \& Jang HC. The effect of TSH suppression on vertebral trabecular bone scores in patients With differentiated thyroid carcinoma. Journal of Clinical Endocrinology and Metabolism 2017102 78-85. (https://doi. org/10.1210/jc.2016-2740)

73 Kim K, Kim IJ, Pak K, Kim SJ, Shin S, Kim BH, Kim SS, Lee BJ \& Jeon YK. Evaluation of bone mineral density using DXA and cQCT in postmenopausal patients under thyrotropin suppressive therapy. Journal of Clinical Endocrinology and Metabolism 2018103 4232-4240. (https://doi.org/10.1210/jc.2017-02704)

74 Tournis S, Antoniou JD, Liakou CG, Christodoulou J, Papakitsou E, Galanos A, Makris K, Marketos H, Nikopoulou S, Tzavara I et al. Volumetric bone mineral density and bone geometry assessed by peripheral quantitative computed tomography in women with differentiated thyroid cancer under TSH suppression. Clinical Endocrinology 201582 197-204. (https://doi.org/10.1111/cen.12560)

75 Moon JH, Jung KY, Kim KM, Choi SH, Lim S, Park YJ, Park DJ \& Jang HC. The effect of thyroid stimulating hormone suppressive therapy on bone geometry in the hip area of patients with differentiated thyroid carcinoma. Bone 201683 104-110. (https:// doi.org/10.1016/j.bone.2015.10.015)

76 Abrahamsen B, Jørgensen HL, Laulund AS, Nybo M, Brix TH \& Hegedüs L. Low serum thyrotropin level and duration of suppression as a predictor of major osteoporotic fractures-the OPENTHYRO register cohort. Journal of Bone and Mineral Research 201429 2040-2050. (https://doi.org/10.1002/jbmr.2244)

77 Mazziotti G, Formenti AM, Frara S, Olivetti R, Banfi G, Memo M, Maroldi R, Giubbini R \& Giustina A. High prevalence of radiological vertebral fractures in women on thyroid-stimulating hormonesuppressive therapy for thyroid carcinoma. Journal of Clinical Endocrinology and Metabolism 2018103 956-964. (https://doi. org/10.1210/jc.2017-01986) 
78 Silverberg SJ, Shane E, de la Cruz L, Dempster DW, Feldman F, Seldin D, Jacobs TP, Siris ES, Cafferty M \& Parisien MV. Skeletal disease in primary hyperparathyroidism. Journal of Bone and Mineral Research 19894 283-291. (https://doi.org/10.1002/jbmr.5650040302)

79 Dempster DW, Müller R, Zhou H, Kohler T, Shane E, Parisien M, Silverberg SJ \& Bilezikian JP. Preserved three-dimensional cancellous bone structure in mild primary hyperparathyroidism. Bone $2007 \mathbf{4 1}$ 19-24. (https://doi.org/10.1016/j.bone.2007.03.020)

80 Silverberg SJ, Locker FG \& Bilezikian JP. Vertebral osteopenia: a new indication for surgery in primary hyperparathyroidism. Journal of Clinical Endocrinology and Metabolism 199681 4007-4012. (https:// doi.org/10.1210/jcem.81.11.8923852)

81 De Geronimo S, Romagnoli E, Diacinti D, D'Erasmo E \& Minisola S. The risk of fractures in postmenopausal women with primary hyperparathyroidism. European Journal of Endocrinology 2006155 415-420. (https://doi.org/10.1530/eje.1.02225)

82 Vignali E, Viccica G, Diacinti D, Cetani F, Cianferotti L, Ambrogini E, Banti C, Del Fiacco R, Bilezikian JP, Pinchera A et al. Morphometric vertebral fractures in postmenopausal women with primary hyperparathyroidism. Journal of Clinical Endocrinology and Metabolism 200994 2306-2312. (https://doi.org/10.1210/jc.2008-2006)

83 Camozzi V, Lumachi F, Mantero F, Piccolo M \& Luisetto G. Phalangeal quantitative ultrasound technology and dual energy $\mathrm{X}$-ray densitometry in patients with primary hyperparathyroidism: influence of sex and menopausal status. Osteoporosis International 200314 602-608. (https://doi.org/10.1007/s00198-003-1407-2)

84 Romagnoli E, Cipriani C, Nofroni I, Castro C, Angelozzi M, Scarpiello A, Pepe J, Diacinti D, Piemonte S, Carnevale V et al. 'Trabecular bone score' (TBS): an indirect measure of bone micro-architecture in postmenopausal patients with primary hyperparathyroidism. Bone 201353 154-159. (https://doi. org/10.1016/j.bone.2012.11.041)

85 Eller-Vainicher C, Morelli V, Ulivieri FM, Palmieri S, Zhukouskaya VV, Cairoli E, Pino R, Naccarato A, Scillitani A, Beck-Peccoz P et al. Bone quality, as measured by trabecular bone score in patients with adrenal incidentalomas with and without subclinical hypercortisolism. Journal of Bone and Mineral Research 201227 2223-2230. (https://doi.org/10.1002/jbmr.1648)

86 Cusano NE, Rubin MR, Silva BC, Tay YD, Williams JM, Agarwal S, Omeragic B, Guo XE \& Bilezikian JP. Skeletal microstructure and estimated bone strength improve following parathyroidectomy in primary hyperparathyroidism. Journal of Clinical Endocrinology and Metabolism 2018103 196-205. (https://doi.org/10.1210/jc.201701932)

87 Chiodini I, Torlontano M, Carnevale V, Trischitta V \& Scillitani A. Skeletal involvement in adult patients with endogenous hypercortisolism. Journal of Endocrinological Investigation $2008 \mathbf{3 1}$ 267-276. (https://doi.org/10.1007/BF03345601)

88 dos Santos CV, Vieira Neto L, Madeira M, Alves Coelho MC, de Mendonça LM, Paranhos-Neto Fde P, Lima IC, Gadelha MR \& Farias ML. Bone density and microarchitecture in endogenous hypercortisolism. Clinical Endocrinology 201583 468-474. (https:// doi.org/10.1111/cen.12812)

89 Chiodini I, Carnevale V, Torlontano M, Fusilli S, Guglielmi G, Pileri M, Modoni S, Di Giorgio A, Liuzzi A, Minisola S et al. Alterations of bone turnover and bone mass at different skeletal sites due to pure glucocorticoid excess: study in eumenorrheic patients with Cushing's syndrome. Journal of Clinical Endocrinology and Metabolism 199883 1863-1867. (https://doi.org/10.1210/ jcem.83.6.4880)

90 Tauchmanovà L, Rossi R, Nuzzo V, del Puente A, Esposito-del Puente A, Pizzi C, Fonderico F, Lupoli G \& Lombardi G. Bone loss determined by quantitative ultrasonometry correlates inversely with disease activity in patients with endogenous glucocorticoid excess due to adrenal mass. European Journal of Endocrinology 2001145 241-247. (https://doi.org/10.1530/eje.0.1450241)
91 Cortet B, Cortet C, Blanckaert F, d'Herbomez M, Marchandise X, Wémeau J-L, Decoulx M \& Dewailly D. Quantitative ultrasound of bone and markers of bone turnover in Cushing's syndrome. Osteoporosis International 200112 117-123. (https://doi.org/10.1007/ s001980170143)

92 Karavitaki N, Ioannidis G, Giannakopoulos F, Mavrokefalos P \& Thalassinos N. Evaluation of bone mineral density of the peripheral skeleton in pre- and postmenopausal women with newly diagnosed endogenous Cushing's syndrome. Clinical Endocrinology 200460 264-270. (https://doi.org/10.1111/j.1365-2265.2004.01968.x)

93 Chiodini I, Morelli V, Masserini B, Salcuni AS, Eller-Vainicher C, Viti R, Coletti F, Guglielmi G, Battista C, Carnevale V et al. Bone mineral density, prevalence of vertebral fractures, and bone quality in patients with adrenal incidentalomas with and without subclinical hypercortisolism: an Italian multicenter study. Journal of Clinical Endocrinology and Metabolism 200994 3207-3214. (https://doi. org/10.1210/jc.2009-0468)

94 Vinolas H, Grouthier V, Mehsen-Cetre N, Boisson A, Winzenrieth R, Schaeverbeke T, Mesguich C, Bordenave L \& Tabarin A. Assessment of vertebral microarchitecture in overt and mild Cushing's syndrome using trabecular bone score. Clinical Endocrinology 2018. (https://doi. org/10.1111/cen.13743)

95 Maurice F, Dutour A, Vincentelli C, Abdesselam I, Bernard M, Dufour H, Le Fur Y, Graillon T, Kober F, Cristofari P et al. Active Cushing syndrome patients have increased ectopic fat deposition and bone marrow fat content compared to cured patients and healthy subjects: a pilot 1H-MRS study. European Journal of Endocrinology 2018179 307-317. (https://doi.org/10.1530/EJE-180318)

96 Chiodini I, Vainicher CE, Morelli V, Palmieri S, Cairoli E, Salcuni AS, Copetti M \& Scillitani A. MECHANISMS IN ENDOCRINOLOGY: Endogenous subclinical hypercortisolism and bone: a clinical review. European Journal of Endocrinology 2016175 R265-R282. (https://doi. org/10.1530/EJE-16-0289)

97 Eller-Vainicher C, Morelli V, Ulivieri FM, Palmieri S, Zhukouskaya VV, Cairoli E, Pino R, Naccarato A, Scillitani A, Beck-Peccoz P et al. Bone quality, as measured by trabecular bone score in patients with adrenal incidentalomas with and without subclinical hypercortisolism. Journal of Bone and Mineral Research 201227 2223-2230. (https://doi.org/10.1002/jbmr.1648)

98 Cawthon PM, Ensrud KE, Laughlin GA, Cauley JA, Dam TT, BarrettConnor E, Fink HA, Hoffman AR, Lau E, Lane NE et al. Sex hormones and frailty in older men: the osteoporotic fractures in men (MrOS) study. Journal of Clinical Endocrinology and Metabolism 200994 3806-3815. (https://doi.org/10.1210/jc.2009-0417)

99 Hernandez CJ. How can bone turnover modify bone strength independent of bone mass? Bone 200842 1014-1020. (https://doi. org/10.1016/j.bone.2008.02.001)

100 Rachner TD, Coleman R, Hadji P \& Hofbauer LC. Bone health during endocrine therapy for cancer. Lancet: Diabetes and Endocrinology 2018 6 901-910. (https://doi.org/10.1016/S2213-8587(18)30047-0)

101 Ramchand SK, Seeman E, Wang XF, Ghasem-Zadeh A, Francis PA, Ponnusamy EJ, Bardin MS, Bui M, Zebaze R, Zajac JD et al. Premenopausal women with early breast cancer treated with estradiol suppression have severely deteriorated bone microstructure. Bone 2017103 131-135. (https://doi.org/10.1016/j.bone.2017.06.024)

102 Greenspan SL, Wagner J, Nelson JB, Perera S, Britton C \& Resnick NM. Vertebral fractures and trabecular microstructure in men with prostate cancer on androgen deprivation therapy. Journal of Bone and Mineral Research 201328 325-332. (https://doi.org/10.1002/ jbmr.1771)

103 Szabo KA, Webber CE, Adachi JD, Tozer R, Gordon C \& Papaioannou A. Cortical and trabecular bone at the radius and tibia in postmenopausal breast cancer patients: a peripheral Quantitative Computed Tomography (pQCT) study. Bone 201148 218-224. (https://doi.org/10.1016/j.bone.2010.09.025) 
104 Gnant M, Pfeiler G, Dubsky PC, Hubalek M, Greil R, Jakesz R, Wette V, Balic M, Haslbauer F, Melbinger E et al. Adjuvant denosumab in breast cancer (ABCSG-18): a multicentre, randomised double-blind, placebo-controlled trial. Lancet 2015386 433-443. (https://doi.org/10.1016/S0140-6736(15)60995-3)

105 Shahinian VB, Kuo YF, Freeman JL \& Goodwin JS. Risk of fracture after androgen deprivation for prostate cancer. New England Journal of Medicine 2005352 154-164. (https://doi.org/10.1056/ NEJMoa041943)

106 Smith MR, Egerdie B, Hernández Toriz N, Feldman R, Tammela TL, Saad F, Heracek J, Szwedowski M, Ke C, Kupic A et al. Denosumab in men receiving androgen-deprivation therapy for prostate cancer. New England Journal of Medicine 2009361 745-755. (https://doi. org/10.1056/NEJMoa0809003)

107 Cianferotti L, Bertoldo F, Carini M, Kanis JA, Lapini A, Longo N, Martorana G, Mirone V, Reginster JY, Rizzoli R et al. The prevention of fragility fractures in patients with non-metastatic prostate cancer: a position statement by the international osteoporosis foundation. Oncotarget 20178 75646-75663. (https://doi.org/10.18632/ oncotarget.17980)

108 Fraenkel M, Geffen DB, Novack V, Shafat T, Mizrakli Y, Ariad S, Koretz M, Norton L \& Siris E. Breast cancer survivors are at an increased risk for osteoporotic fractures not explained by lower BMD: a retrospective analysis. NPJ Breast Cancer 20151 15010. (https://doi. org/10.1038/npjbcancer.2015.10)

109 James H 3rd, Aleksic I, Bienz MN, Pieczonka C, Iannotta P, Albala D, Mariados N, Mouraviev V \& Saad F. Comparison of fracture risk assessment tool score to bone mineral density for estimating fracture risk in patients with advanced prostate cancer on androgen deprivation therapy. Urology 201484 164-168. (https://doi. org/10.1016/j.urology.2013.12.071)

110 Kalder M, Hans D, Kyvernitakis I, Lamy O, Bauer M \& Hadji P. Effects of exemestane and tamoxifen treatment on bone texture analysis assessed by TBS in comparison with bone mineral density assessed by DXA in women with breast cancer. Journal of Clinical Densitometry 201417 66-71. (https://doi.org/10.1016/j.jocd.2013.03.003)

111 Hong AR, Kim JH, Lee KH, Kim TY, Im SA, Kim TY, Moon HG, Han WS, Noh DY, Kim SW et al. Long-term effect of aromatase inhibitors on bone microarchitecture and macroarchitecture in nonosteoporotic postmenopausal women with breast cancer. Osteoporosis International 201728 1413-1422. (https://doi.org/10.1007/s00198016-3899-6)

112 María RS, Marta PM, Sonia S, Natalia GG, Tamara M, Ignasi T, Maria MG, Jaime RM, Adolfo DP, Joan A et al. TBS and BMD at the end of AI-therapy: a prospective study of the B-ABLE cohort. Bone 201692 1-8. (https://doi.org/10.1016/j.bone.2016.08.008)

113 Kalder M, Kyvernitakis I, Albert US, Baier-Ebert M \& Hadji P. Effects of zoledronic acid versus placebo on bone mineral density and bone texture analysis assessed by the trabecular bone score in premenopausal women with breast cancer treatment-induced bone loss: results of the ProBONE II substudy. Osteoporosis International 201526 353-360. (https://doi.org/10.1007/s00198-014-2955-3)

114 Mariotti V, Page DB, Davydov O, Hans D, Hudis CA, Patil S, Kunte S, Girotra M, Farooki A \& Fornier MN. Assessing fracture risk in early stage breast cancer patients treated with aromatase-inhibitors: an enhanced screening approach incorporating trabecular bone score. Journal of Bone Oncology 20177 32-37. (https://doi.org/10.1016/j. jbo.2016.10.004)

115 Chang G, Boone S, Martel D, Rajapakse CS, Hallyburton RS, Valko M, Honig S \& Regatte RR. MRI assessment of bone structure and microarchitecture. Journal of Magnetic Resonance Imaging 201746 323-337. (https://doi.org/10.1002/jmri.25647)

116 Schwaiger BJ, Kopperdahl DL, Nardo L, Facchetti L, Gersing AS, Neumann J, Lee KJ, Keaveny TM \& Link TM. Vertebral and femoral bone mineral density and bone strength in prostate cancer patients assessed in phantomless PET/CT examinations. Bone $2017 \mathbf{1 0 1}$ 62-69. (https://doi.org/10.1016/j.bone.2017.04.008)

117 Kanis JA, Oden A, Johansson H, Borgström F, Ström O \& McCloskey E. FRAX and its application to clinical practice. Bone 2009 44 734-743. (https://doi.org/10.1016/j.bone.2009.01.373)

118 Kanis JA, Cooper C, Rizzoli R, Reginster JY \& Scientific Advisory Board of the European Society for Clinical and Economic Aspects of Osteoporosis (ESCEO) and the Committees of Scientific Advisors and National Societies of the International Osteoporosis Foundation (IOF). European guidance for the diagnosis and management of osteoporosis in postmenopausal women. Osteoporosis International 201930 3-44. (https://doi.org/10.1007/s00198-018-4704-5)

119 Rizzoli R, Body JJ, DeCensi A, Reginster JY, Piscitelli P, Brandi ML \& European Society for Clinical and Economical aspects of Osteoporosis and Osteoarthritis (ESCEO). Guidance for the prevention of bone loss and fractures in postmenopausal women treated with aromatase inhibitors for breast cancer: an ESCEO position paper. Osteoporosis International 201223 2567-2576. (https://doi.org/10.1007/s00198011-1870-0)

120 Grossman JM, Gordon R, Ranganath VK, Deal C, Caplan L, Chen W, Curtis JR, Furst DE, McMahon M, Patkar NM et al. American College of Rheumatology 2010. Recommendation for the prevention and treatment of glucocorticoid-induced osteoporosis. Arhtritis Care Research 201062 1515-1526. (https://doi.org/10.1002/acr.20295)

121 Cianferotti L, Bertoldo F, Carini M, Kanis JA, Lapini A, Longo N, Martorana G, Mirone V, Reginster JY, Rizzoli R et al. The prevention of fragility fractures in patients with non-metastatic prostate cancer: a position statement by the international osteoporosis foundation. Oncotarget 20178 75646-75663. (https://doi.org/10.18632/ oncotarget.17980)

122 Hadji P, Aapro MS, Body JJ, Gnant M, Brandi ML, Reginster JY, Zillikens MC, Glüer CC, de Villiers T, Baber R et al. Management of aromatase inhibitor-associated bone loss (AIBL) in postmenopausal women with hormone sensitive breast cancer: joint position statement of the IOF, CABS, ECTS, IEG, ESCEO, IMS, and SIOG. Journal of Bone Oncology 20177 1-12. (https://doi.org/10.1016/j. jbo.2017.03.001)

123 European AIDS clinical society: guidelines prevention and management of non-infection co-morbidities in HIV, 9.1 version octob 2018 section: non infectious comorbidities in HIV. (available at: http://www.eacsociety.org/guidelines/eacs-guidelines/eacsguidelines.html)

124 Prawiradilaga RS, Gunmalm V, Lund-Jacobsen T, Helge EW, Brøns C Andersson M \& Schwarz P. FRAX calculated without BMD resulting in a higher fracture risk than that calculated with BMD in women with early breast cancer. Journal of Osteoporosis 201844636028. (https://doi.org/10.1155/2018/4636028)

125 Premaor M, Parker RA, Cummings S, Ensrud K, Cauley JA, Lui LY, Hillier T, Compston J \& Study of Osteoporotic Fractures (SOF) Research Group. Predictive value of FRAX for fracture in obese older women. Journal of Bone and Mineral Research 201328 88-95. (https:// doi.org/10.1155/2018/4636028)

126 James H 3rd, Aleksic I, Bienz MN, Pieczonka C, Iannotta P, Albala D, Mariados N, Mouraviev V \& Saad F. Comparison of fracture risk assessment tool score to bone mineral density for estimating fracture risk in patients with advanced prostate cancer on androgen deprivation therapy. Urology 201484 164-168. (https://doi. org/10.1016/j.urology.2013.12.071)

127 McCloskey EV, Odén A, Harvey NC, Leslie WD, Hans D, Johansson H, Barkmann R, Boutroy S, Brown J, Chapurlat R et al. A meta-analysis of trabecular bone score in fracture risk prediction and its relationship to FRAX. Journal of Bone and Mineral Research 201631 940-948. (https://doi.org/10.1002/jbmr.2734)

128 Muñoz-Torres M, Manzanares Córdova R, García-Martín A, AvilésPérez MD, Nieto Serrano R, Andújar-Vera F \& García-Fontana B. 
Usefulness of trabecular bone score (TBS) to identify bone fragility in patients with primary hyperparathyroidism. Journal of Clinical Densitometry 201822 162-170.

129 Reynolds RM, Dennison EM, Walker BR, Syddall HE, Wood PJ, Andrew R, Phillips DI \& Cooper C. Cortisol secretion and rate of bone loss in a population-based cohort of elderly men and women. Calcified Tissue International 200577 134-138. (https://doi. org/10.1007/s00223-004-0270-2)

130 Osella G, Ventura M, Ardito A, Allasino B, Termine A, Saba L, Vitetta R, Terzolo M \& Angeli A. Cortisol secretion, bone health, and bone loss: a cross-sectional and prospective study in normal nonosteoporotic women in the early postmenopausal period. European Journal of Endocrinology 2012166 855-860. (https://doi.org/10.1530/ EJE-11-0957)

131 Tomlinson JW, Walker EA, Bujalska IJ, Draper N, Lavery GG, Cooper MS, Hewison M \& Stewart PM. 11Beta-hydroxysteroid dehydrogenase type 1: a tissue-specific regulator of glucocorticoid response. Endocrine Reviews 200425 831-866. (https://doi. org/10.1210/er.2003-0031)

132 Hwang JY, Lee SH, Kim GS, Koh JM, Go MJ, Kim YJ, Kim HC, Kim TH, Hong JM, Park EK et al. HSD11B1 polymorphisms predicted bone mineral density and fracture risk in postmenopausal women without a clinically apparent hypercortisolemia. Bone 200945 1098-1103. (https://doi.org/10.1016/j.bone.2009.07.080)

133 Koper JW, van Rossum EF \& van den Akker EL. Glucocorticoid receptor polymorphisms and haplotypes and their expression in health and disease. Steroids 201492 62-73. (https://doi. org/10.1016/j.steroids.2014.07.015)

134 Morelli V, Donadio F, Eller-Vainicher C, Cirello V, Olgiati L, Savoca C, Cairoli E, Salcuni AS, Beck-Peccoz P \& Chiodini I. Role of glucocorticoid receptor polymorphism in adrenal incidentalomas. European Journal of Clinical Investigation 201040 803-811. (https:// doi.org/10.1111/j.1365-2362.2010.02330.x)

135 Kim BJ, Kwak MK, Ahn SH, Kim H, Lee SH \& Koh JM. Lower trabecular bone score in patients with primary aldosteronism: human skeletal deterioration by aldosterone excess. Journal of
Clinical Endocrinology and Metabolism 2018103 615-621. (https://doi. org/10.1210/jc.2017-02043)

136 Notsu M, Yamauchi M, Yamamoto M, Nawata K \& Sugimoto T. Primary aldosteronism as a risk factor for vertebral fracture. Journal of Clinical Endocrinology and Metabolism 2017102 1237-1243. (https:// doi.org/10.1210/jc.2016-3206)

137 Salcuni AS, Palmieri S, Carnevale V, Morelli V, Battista C, Guarnieri V, Guglielmi G, Desina G, Eller-Vainicher C, Beck-Peccoz P et al. Bone involvement in aldosteronism. Journal of Bone and Mineral Research 201227 2217-2222. (https://doi.org/10.1002/jbmr.1660)

$138 \mathrm{Wu}$ VC, Chang CH, Wang CY, Lin YH, Kao TW, Lin PC, Chu TS, Chang YS, Chen L, Wu KD et al. Risk of fracture in primary aldosteronism: a population-based cohort study. Journal of Bone and Mineral Research 201732 743-752. (https://doi.org/10.1002/ jbmr.3033)

139 Cannone V, Buglioni A, Sangaralingham SJ, Scott C, Bailey KR, Rodeheffer R, Redfield MM, Sarzani R \& Burnett JC Jr. Aldosterone, hypertension, and antihypertensive therapy: insights from a general population. Mayo Clinic Proceedings 201893 980-990. (https://doi. org/10.1016/j.mayocp.2018.05.027)

140 Bacchetta J, Bardet C \& Prié D. Physiology of FGF23 and overview of genetic diseases associated with renal phosphate wasting. Metabolism: Clinical and Experimental 2019 Epub. (https://doi.org/10.1016/j. metabol.2019.01.006)

141 Simon S, Resch H, Klaushofer K, Roschger P, Zwerina J \& Kocijan R. Hypophosphatasia: from diagnosis to treatment. Current Rheumatology Reports 201820 69. (https://doi.org/10.1007/s11926018-0778-5)

142 Lentle B, Koromani F, Brown JP, Oei L, Ward L, Goltzman D, Rivadeneira F, Leslie WD, Probyn L, Prior J et al. The radiology of osteoporotic vertebral fractures revisited. Journal of Bone and Mineral Research 201934 409-418. (https://doi.org/10.1002/jbmr.3669)

143 Hans D, Šteňová E \& Lamy O. The trabecular bone score (TBS) complements DXA and the FRAX as a fracture risk assessment tool in routine clinical practice. Current Osteoporosis Reports 201715 521-531. (https://doi.org/10.1007/s11914-017-0410-z)

Received 12 December 2018

Revised version received 25 February 2019

Accepted 29 April 2019 